\title{
Análise numérica térmica da alvenaria estrutural em situação de incêndio: isolamento térmico entre ambientes
}

\author{
Numerical thermal analysis of structural masonry in fire \\ situations: thermal insulation between adjacent rooms
}

\section{Paulo Roberto de Oliveira Carvalho \\ Davi Fagundes Leal Jorge Munaiar Neto}

\section{Resumo}

A

segurança das edificações contra incêndios é um dos requisitos a serem considerados no dimensionamento estrutural, uma vez que o aumento da temperatura causa a redução das propriedades mecânicas dos materiais. No entanto, as normas brasileiras atuais voltadas à alvenaria estrutural não contemplam a ação térmica, sendo necessária a consulta a normas estrangeiras, cujos parâmetros são definidos conforme os materiais utilizados em seus países. Nesse sentido, o presente trabalho objetiva analisar numericamente o isolamento térmico de paredes de alvenaria estrutural de blocos de concreto com base em comparações com resultados experimentais apresentados em Dupim (2019). Como estratégia, foram calibradas as propriedades térmicas dos materiais de acordo com os limites propostos pelo Eurocode e inseridas curvas de evolução de temperatura nas faces externas e internas dos blocos. Os modelos numéricos desenvolvidos permitem obter resultados de evolução de temperatura ao longo da seção transversal, tendo apresentado boa correlação com os resultados experimentais. Considerando paredes com $14 \mathrm{~cm}$ de espessura, o tempo de resistência ao fogo quanto ao critério de isolamento térmico entre ambientes resultou igual a $60 \mathrm{~min}$, valor próximo dos $62 \mathrm{~min}$ obtido experimentalmente.

Palavras-chave: Alvenaria estrutural. Incêndio. Isolamento térmico. Análise numérica. Modelo térmico.

${ }^{1}$ Paulo Roberto de Oliveira Carvalho UUniversidade de São Paulo São Carlos - SP - Brasil

${ }^{2}$ Davi Fagundes Leal IInstituto Federal de Educação, Ciência e Tecnologia Fluminense Campos dos Goytacazes - RJ - Brasil

\footnotetext{
3Jorge Munaiar Neto 3Universidade de São Paulo São Carlos - SP - Brasil

Recebido em 13/07/20 Aceito em 07/03/21
}

\section{Abstract}

Fire situations must be considered in structural design to minimize risks to the safety of buildings, since high temperatures ultimately result in the decrease of the mechanical properties of building materials and lead to the spread of flames to adjacent rooms. However, Brazilian standards do not provide design procedures for evaluating structural masonry at high temperatures, therefore engineers usually apply foreign standards, which are based on the thermal properties of the materials used in their countries. This study aims to evaluate the thermal behaviour of concrete masonry walls in fire situations by means of numerical analysis, taking the experimental results presented in Dupim (2019) as reference. The thermal properties of the materials in the numerical model were calibrated according to the Eurocode, and temperature increases on the masonry surfaces were simulated by using temperature-time curves obtained in experimental tests. The numerical results are in good agreement with the experimental measurements, which were carried out at various points in the masonry cross section, with maximum temperature differences below $10 \%$. The fire resistance of a $14 \mathrm{~cm}$-thick masonry wall, according to the thermal insulation criterion, was equal to 60 min in the numerical analysis, which is close to the experimental result of 62 min taken as reference.

Keywords: Structural masonry. Fire. Thermal insulation. Numerical analysis. Thermal analysis.

CARVALHO, P. R. de O.; LEAL, D. F.; MUNAIAR NETO, J. Análise numérica térmica da alvenaria estrutural em situação de incêndio: isolamento térmico entre ambientes. Ambiente Construído, Porto Alegre, v. 21, n. 4, p. 65-87, out./dez. 2021. 


\section{Introdução}

A alvenaria estrutural é formada por unidades (blocos ou tijolos) unidos por juntas de argamassa, além de graute e armaduras, sendo as funções destes últimos elementos dependentes da classificação do sistema. As unidades usuais são normalmente blocos vazados de concreto ou cerâmicos. Nesse sistema construtivo, as paredes exercem função de vedação e agem também como elemento estrutural, tendo em vista sua elevada resistência aos esforços mecânicos, sobretudo quando solicitadas predominantemente por tensões de compressão. Entre as principais vantagens podem ser citadas economia de tempo e de material, redução do volume de resíduos gerados na obra, produtividade elevada e diminuição de custos.

Quanto aos materiais componentes da alvenaria estrutural, algumas características são buscadas para que sejam incorporados ao sistema construtivo. No caso das unidades, por exemplo, os materiais constituintes devem apresentar adequada resistência à compressão, bem como boa capacidade de aderência à argamassa de assentamento e dimensões uniformes. Apesar do pouco conhecimento existente acerca desse sistema construtivo em situações de incêndio, outra característica relevante às unidades se refere à elevada resistência ao fogo (SOARES, 2010).

Em relação aos incêndios, a média anual de ocorrências no Brasil, de acordo com a Secretaria Nacional de Segurança Pública (Senasp), do Ministério da Justiça, é de 267 mil (incluindo ocorrências florestais e residenciais). O International Association of Fire and Rescue Service (CENTRE..., 2016), que possui base de dados de diversos grandes centros de 31 países, verificou que os incêndios em edificações foram responsáveis por $38 \%$ dos casos. Dessa forma, é consenso o fato de que o dimensionamento apenas em temperatura ambiente não é mais suficiente para a garantia da segurança estrutural, havendo a necessidade da verificação da estrutura também em elevadas temperaturas.

No Brasil, apesar das exigências da NBR 15575-4 (ABNT, 2013) quanto ao desempenho das estruturas em relação ao fogo, ainda não há norma técnica específica para alvenaria estrutural em situações de incêndio, ao contrário dos casos das estruturas de concreto, de aço e mistas. Em virtude dessa lacuna, o Corpo de Bombeiros do Estado de São Paulo, por exemplo, por meio da Instrução Técnica no 08 (CORPO..., 2011), recomenda o uso do Eurocode 6 (EUROPEAN..., 2005a) ou de normas internacionais similares para o dimensionamento de alvenaria estrutural em situação de incêndio. Ressalta-se que os materiais constituintes da alvenaria no Brasil podem apresentar grandes divergências quanto a suas propriedades térmicas em relação aos materiais estrangeiros, podendo comprometer a confiabilidade dos resultados quando da aplicação direta dessas normas.

O Eurocode 6 (EUROPEAN..., 2005a) permite avaliar a resistência ao fogo da alvenaria por meio da verificação de quatro critérios, os quais englobam a verificação da resistência mecânica (R), da estanqueidade (E), do isolamento térmico (I) e do impacto mecânico (M). Neste artigo se analisou o comportamento da alvenaria estrutural apenas segundo o critério de isolamento térmico, o qual é fator determinante para questões de propagação de calor entre ambientes adjacentes quando da ocorrência de incêndio em dado setor da edificação. Nesse caso, a resistência ao fogo é dada pelo tempo relativo ao aumento de $180^{\circ} \mathrm{C}$ em qualquer ponto da face da parede não exposta ao incêndio, ou, ainda, quando a elevação de temperatura média dessa mesma face ultrapassa $140{ }^{\circ} \mathrm{C}$. O menor valor entre esses dois requisitos é considerado, então, o tempo de resistência ao fogo da parede em relação ao critério de isolamento térmico.

Tal verificação é de suma importância para a avaliação do desempenho e da segurança das edificações, uma vez que o isolamento térmico promovido pelas paredes está diretamente relacionado ao risco de propagação do incêndio de um ambiente para outro da construção, ou mesmo para edificações vizinhas. Adicionalmente, o conhecimento da elevação da temperatura no interior das paredes possibilita realizar, com base em métodos simplificados de cálculo, estimativas quanto à resistência ao fogo dos elementos estruturais segundo o critério de resistência mecânica.

Os custos envolvidos em experimentos em elevadas temperaturas são substancialmente consideráveis em virtude de infraestrutura necessária, a qual deve considerar equipamentos e materiais específicos para sua execução adequada. Nesse sentido, a modelagem numérica se torna uma alternativa interessante para análises nessas circunstâncias, uma vez que, após a calibração e validação dos modelos a partir de resultados experimentais, essas mesmas análises apresentam eficácia, versatilidade e obtenção de resultados em menores tempos.

Diante do exposto, o presente trabalho simula numericamente o comportamento térmico de pequenas paredes de alvenaria estrutural constituídas de blocos vazados de concreto, considerando a utilização do 
código computacional ABAQUS versão 6.14, cujas ferramentas disponibilizadas têm por base o Método dos Elementos Finitos. Após a validação feita com base em resultados experimentais presentes na literatura, algumas análises complementares foram desenvolvidas com o intuito de avaliar a influência de fatores que interferem no critério de isolamento térmico, como a variação das condições de confinamento na face oposta ao fogo, a espessura da parede e as propriedades térmicas dos materiais.

\section{Referencial teórico}

Andreini et al. (2014) comentam que são diversos os parâmetros que podem interferir no comportamento da alvenaria em situação de incêndio. Citam, entre outros, a forma, a geometria, a textura dos blocos, a espessura das juntas de argamassa, o teor de umidade dos componentes, as dimensões e restrições impostas à expansão térmica e a forma de exposição ao fogo. Adicionalmente, em Bonitese (2007) é mencionada a grande influência que a composição química dos materiais causa no sistema em resposta às diferentes propriedades físico-químicas dos materiais envolvidos na composição dos blocos e argamassas, as quais se alteram diferentemente com o aquecimento daqueles.

Blocos com maiores espessuras apresentam maiores resistências quanto ao isolamento térmico, uma vez que existe maior espaço a ser percorrido para transferência de calor por condução. Com a existência dos vazados dos blocos, ocorre alteração dos mecanismos de transferência de calor no interior da alvenaria, assim como convecção e radiação nos septos vazados, resultando em alteração da condutividade térmica efetiva e do calor absorvido pela parede se comparadas com paredes de blocos maciços. A variação do formato e da distribuição dos vazados internos também exerce influência no isolamento térmico. Em ensaios realizados por Al-Hadhrami e Ahmad (2009) se verificou que blocos com dois vazados apresentam aumento significativo do isolamento térmico em relação a blocos com um único vazado, considerando ambos os casos com dimensões idênticas dos blocos.

O material constituinte do bloco tem interferência direta na velocidade em que ocorre a transferência de calor devido às propriedades térmicas inerentes de cada material. Paredes construídas com materiais com menor condutividade térmica, por exemplo, possuem maior isolamento térmico. O mesmo ocorre com aquelas construídas com materiais que possuem maior calor específico, os quais demandam maior absorção de calor para que ocorra variação de temperatura ao longo da espessura da parede. A atuação conjunta dessas duas propriedades térmicas, juntamente com a massa específica (difusividade térmica do material), determina a eficiência da parede quanto ao critério de isolamento térmico.

Rosemann (2011) explana sobre as mudanças que ocorrem nos mecanismos de transferência de calor na ocasião de incêndio em apenas uma das faces do elemento estrutural. A mudança de estado físico da umidade presente no concreto faz com que ocorra o transporte de massa através do meio poroso, acarretando interferências na transferência de calor ao longo da espessura do elemento. Da mesma forma, Al Nahhas et al. (2007) defendem que a densidade e a porosidade são de alta relevância nesse tipo de análise, principalmente devido ao fato de a umidade existente no interior dos poros consumir parte do calor que atravessa a espessura da parede, ocasionando sua evaporação.

Quanto ao processo construtivo, a existência de enchimentos nos vazios dos blocos exerce grande influência quanto ao isolamento. O grauteamento, por exemplo, utilizado para melhorar as características mecânicas e estruturais das paredes, tende a aumentar significativamente o isolamento térmico, pois a quantidade de calor absorvido pela parede aumenta em uma proporção maior se comparada ao aumento da condutividade térmica (OLIVEIRA, 1998). A melhoria do isolamento térmico pode ser promovida também mediante o enchimento dos vazados com areia ou outros materiais de baixa massa específica.

Outra forma de obter ganho no isolamento térmico se volta ao uso de revestimentos das faces das paredes. Com a camada de revestimento, há acréscimo na espessura da parede, aumentando o tempo para a elevação da temperatura na face oposta. Oliveira (1998) alerta sobre a limitação do tempo em que o revestimento na face exposta ao fogo se mantém solidário, uma vez que o ganho quanto ao isolamento fica limitado a sua integridade na parede. Chichierchio (1990) ensaiou variações de paredes com e sem revestimentos. No caso, obteve resistência quanto ao critério de isolamento térmico de 90 min na situação sem revestimento e de 120 min considerando revestimento de cimento e areia com $1,5 \mathrm{~cm}$ em ambas as faces.

Para situações em que ocorre o incêndio inicialmente em apenas uma das faces da alvenaria, como são os casos de ambientes compartimentados, por exemplo, um arqueamento da parede na direção do fogo é verificado em Nadjai et al. (2006). Isso acontece devido à existência de um gradiente térmico ao longo da espessura da parede, ocorrendo maior dilatação nas partes mais aquecidas. Nadjai et al. (2006) acrescenta 
que essa situação faz com que as cargas aplicadas resultem em excentricidades majoradas, gerando momentos de segunda ordem e aumentando as solicitações sobre as paredes. Para o encurvamento, as principais variáveis são o coeficiente de dilatação, a condutividade térmica do material e a existência de carregamentos verticais sobre o elemento estrutural, cuja ocorrência não inibe a deflexão, embora a reduza. Dessa forma, o carregamento resulta benéfico nos estágios iniciais, mas, após um longo período de exposição ao fogo, a parede tende a apresentar instabilidade lateralmente, gerando altas tensões em função do aparecimento de momentos induzidos pela deformação lateral. Quanto às vinculações e restrições, estas podem gerar esforços internos adicionais, uma vez que impedem deslocamentos devido à expansão do material com o aumento da temperatura.

Al Nahhas et al. (2007) realizaram estudos experimentais com elevação de temperatura seguindo a curva padrão proposta pela ISO 834-1 (INTERNATIONAL..., 1999) em blocos celulares. Foram posicionados termopares ao longo da espessura desses blocos para análise da elevação de temperatura ao longo da seção transversal dos blocos. Foi verificada, para temperaturas próximas a $100{ }^{\circ} \mathrm{C}$, a ocorrência de patamares maiores ao aumentar a distância da face exposta ao fogo. Esse tipo de situação, conforme definido na última referência, se manifesta em resposta à ocorrência de mudança de fase da água livre nos poros do bloco, o que demanda a absorção de energia térmica para o processo de evaporação da água.

Em Rosemann (2011) foi avaliada a resistência ao fogo de paredes de alvenaria estrutural de blocos cerâmicos, com dimensões iguais a 2,70x2,60x0,14 m, por meio de métodos experimentais quanto ao critério do isolamento térmico. A elevação de temperatura no forno seguiu a curva de incêndio padrão da ISO 834-1 (INTERNATIONAL..., 1999), cujas análises buscaram quatro diferentes situações:

(a) paredes de blocos sem qualquer material de preenchimento:

- com revestimento em argamassa de 1,5 cm de espessura; ou

- sem revestimento.

(b) paredes de blocos vazados preenchidos com areia :

- com revestimento em argamassa de 1,5 cm de espessura; ou

- sem revestimento.

As paredes sem preenchimento, quando sem revestimento, apresentaram resistência ao fogo durante 106 min e, quando com revestimentos, durante 196 min. Já as amostras com preenchimento dos vazados com areia apresentaram, quando sem revestimento, resistência ao fogo por 243 min e, quando revestidas, por 405 min.

Rigão (2012) avaliou experimentalmente o comportamento de prismas de alvenaria estrutural de blocos cerâmicos em temperatura ambiente e submetidos a elevadas temperaturas, com vistas à verificação da resistência residual. Após aquecimento de até $400{ }^{\circ} \mathrm{C}$ e resfriamento natural, obteve resistência residual à compressão da ordem de $73 \%$, enquanto para aquecimento até $900{ }^{\circ} \mathrm{C}$, resistência residual à compressão da ordem de $49 \%$.

Em Santos et al. (2017) se procedeu a análise numérica com vistas ao comportamento termoestrutural de alvenaria de blocos cerâmicos com base em estudos experimentais desenvolvidos em Rosemann (2011) e em Rigão (2012), utilizando o código ABAQUS e a macromodelagem por meio de elementos do tipo C3D8R. Os autores concluíram que o nível de carga afeta diretamente o comportamento termoestrutural da alvenaria, e negativamente a resistência ao fogo, destacando-se que o carregamento não foi elevado até a ruptura. Os modelos numéricos apresentaram boa proximidade entre as curvas de temperatura experimentais e numéricas em função do tempo de exposição ao fogo.

Em Rodovalho (2018) se estudou numericamente o comportamento estrutural e térmico de blocos e prismas de concreto, com e sem revestimento, de espessura igual a $1,5 \mathrm{~cm}$, utilizando o pacote computacional ABAQUS e os modelos de plasticidade e dano para representar o comportamento não linear dos blocos e das juntas de argamassa. No modelo idealizado não houve consideração quanto a deslocamento relativo na interface entre argamassa e bloco. Nos modelos numéricos estruturais se utilizaram elementos tridimensionais contínuos com integração reduzida (C3D8R), cujo carregamento se deu por meio de controle de deslocamentos, com o objetivo de simular os ensaios realizados em Oliveira (2014), obtendo-se curvas tensão-deformação próximas às experimentais até o instante da ruptura. Para a modelagem de transferência de calor, a malha para os prismas de blocos de concreto foi a mesma utilizada para o modelo estrutural com elementos do tipo DC3D8 relacionados à transferência de calor dos blocos e argamassa. A massa de ar presente nos vazados dos blocos foi modelada considerando elementos finitos do tipo FC3D8, onde a transferência de calor é simulada por meio de ferramentas que consideram a interação fluido-estrutura. A 
transferência de calor considerada para o meio sólido se deu por condução, enquanto entre o ar e o material do bloco por convecção e radiação. O aquecimento adotado respeitou a curva ISO 834-1 (INTERNANTIONAL..., 1999) em uma das faces. Numericamente, obteve resistência ao fogo quanto ao critério de isolamento térmico igual a 86 min para a situação sem revestimento, 106 min para situação com revestimento em uma das faces, e 137 min para a consideração de revestimento em ambas as faces.

Em Dupim (2019) foram ensaiadas pequenas paredes de alvenaria estrutural de blocos de concreto em situação de incêndio, com elevação de temperatura de acordo com a curva ISO 834-1 (INTERNATIONAL..., 1999) em um forno horizontal, com o intuito de avaliar a resistência residual dos elementos. Foram adotadas duas configurações para o estudo, uma com exposição ao fogo em todas as faces da parede e outra com paredes formando um trio fechado isolado com manta cerâmica e placa de gesso sobre elas. O objetivo desta última configuração foi simular a compartimentação de edifícios. Para paredes formadas por blocos com resistência nominal de 4,0 $\mathrm{MPa}$, obteve resistência pós-fogo igual a $14 \% \mathrm{em}$ relação a sua resistência à temperatura ambiente para a situação com exposição ao fogo em todas as faces, enquanto na configuração em trio a mesma relação foi igual a 46\%. Para paredes com blocos de 10,0 MPa, o valor obtido para essa mesma relação considerando fogo em ambas as faces resultou igual a 13\%.

Apesar dos estudos citados, existem poucas pesquisas em âmbito nacional considerando a variação de temperatura em alvenaria estrutural, sobretudo com o objetivo de prover curvas referentes às propriedades térmicas, como no caso do calor específico e da condutividade térmica. O presente trabalho faz parte de um conjunto de pesquisas paralelas desenvolvidas no Departamento de Engenharia de Estruturas da EESC/USP objetivando caracterizar o comportamento térmico e estrutural da alvenaria de blocos vazados de concreto em situação de incêndio. Nesse contexto, juntamente com o trabalho aqui proposto, foram realizados os trabalhos apresentados em Carvalho (2019), em Dupim (2019) e em Rodovalho (2018), os quais tiveram desenvolvimento nos contextos experimental e numérico.

A segunda referência apresenta grande quantidade de resultados experimentais, incluindo curvas de evolução da temperatura em diversos pontos da seção transversal da alvenaria, razão pela qual foi tomada como principal referência para a calibração dos modelos numéricos aqui apresentados, cujos detalhes são apresentados a seguir.

\section{Método}

O comportamento térmico da alvenaria estrutural de blocos de concreto é aqui avaliado com base em análises numéricas realizadas pelo Método dos Elementos Finitos, tomando-se como referência resultados experimentais presentes na literatura. Além disso, foram realizados ensaios experimentais complementares com blocos representativos da alvenaria sob diferentes condições de exposição ao fogo visando alimentar o modelo numérico térmico com informações essenciais para a estratégia de modelagem aqui proposta.

A modelagem numérica foi realizada com o software ABAQUS, versão 6.14. Os elementos finitos utilizados foram os do tipo DC3D8 (8-node linear brick), isto é, elementos de difusão de calor com oito nós (interpolação linear), os quais se aplicam para fins de análise exclusivamente térmica. Optou-se pela análise transiente, na qual as propriedades térmicas dos materiais e a distribuição de temperatura variam em função do tempo. As calibrações das propriedades térmicas foram feitas com base em um estudo experimental desenvolvido paralelamente ao presente trabalho, conforme apresentado em Dupim (2019), em que foram estudadas pequenas paredes de alvenaria estrutural de blocos vazados de concreto com largura de $14 \mathrm{~cm}$, resistência característica à compressão de 4,0 MPa, argamassamento total e com exposição por cerca de 70 min ao incêndio padrão proposto na ISO 834 (INTERNANTIONAL..., 1999) em uma ou em ambas as faces.

Nos itens que seguem estão apresentadas as definições da geometria, das condições de contorno e das propriedades dos materiais utilizadas na modelagem numérica, as quais permitiram validar o modelo numérico com análises complementares.

\section{Definições preliminares}

A técnica de modelagem escolhida para esta análise foi a micromodelagem detalhada, conforme utilizada por Rodovalho (2018) em análise térmica de prismas de alvenaria estrutural de blocos de concreto. Com essa técnica, cada material componente da alvenaria é modelado individualmente, com suas propriedades.

Os blocos foram modelados com largura de $14 \mathrm{~cm}$, comprimento de $39 \mathrm{~cm}$ e altura de $19 \mathrm{~cm}$. Por serem blocos vazados, as espessuras de seus septos longitudinais e transversais foram fixadas em $3,0 \mathrm{~cm}$, de acordo com medidas realizadas experimentalmente. As juntas de argamassa foram fixadas em $1 \mathrm{~cm}$ de espessura, 
resultando, para a pequena parede, largura total igual a $79 \mathrm{~cm}$ e altura igual a $99 \mathrm{~cm}$, conforme esquematiza a Figura 1.

A discretização dos blocos foi feita de forma a garantir a geração de dada malha com, no mínimo, três elementos finitos ao longo da espessura dos septos, resultando em elementos com dimensões de aproximadamente 1,0 cm. Em Carvalho (2019) se constatou que uma malha de elementos finitos fortemente discretizada não resulta em melhoria quanto aos resultados obtidos, mesmo em análises voltadas ao comportamento estrutural. $\mathrm{O}$ uso de elementos com dimensões de $1 \mathrm{~cm}$, adotado na última referência, foi suficiente para proporcionar resultados satisfatórios com esforço computacional reduzido. A Figura 2 ilustra o bloco já discretizado em elementos finitos.

Em Carvalho (2019) também foi verificado o uso da geometria troncocônica dos vazados dos blocos, situação mais próxima à real em detrimento à geometria prismática, conforme a Figura 2. Verificou-se que, em termos de valores de tensão, de deformação e de temperatura, a diferença entre os modelos foi inferior a $4 \%$, o que justifica o uso de geometria simplificada.

\section{Condições de contorno}

\section{Face exposta e não exposta ao fogo}

As condições de contorno do modelo numérico térmico foram criadas de acordo com os experimentos apresentados em Dupim (2019). O forno horizontal utilizado é alimentado a gás natural, possui dimensões

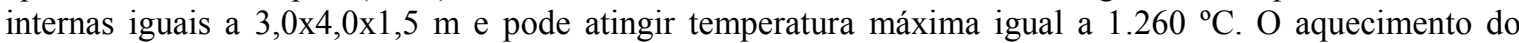
forno é realizado por meio de oito queimadores Kromschröder, com potência total de $3.600 \mathrm{~kW}$. Nesses experimentos, além de corpos de prova expostos ao fogo em ambas as faces, uma composição de pequenas paredes em trio foi testada em um forno de ensaios de forma a simular a ação do fogo em apenas uma face da alvenaria (parede atuando como elemento de compartimentação), conforme ilustrado na Figura 3. Essa configuração, no entanto, não segue as normas técnicas nacionais e internacionais de avaliação de sistemas construtivos, as quais consideram uma superfície exposta à curva ISO 834 (INTERNATIONAL..., 1999) e de outra exposta ao ambiente, isoladas entre si.

Assim, a elevação da temperatura na face exposta ao fogo da alvenaria foi definida no modelo numérico de acordo com a curva de incêndio padrão proposta na ISO 834 (INTERNATIONAL..., 1999), enquanto à face não exposta foi associada uma taxa de aquecimento equivalente às medidas de temperatura no interior do trio de paredes, obtidas por meio de termopares durante os ensaios.

Figura 1 - Esquematização das dimensões da pequena parede (a) e do bloco de concreto (b) (medidas em centímetros)

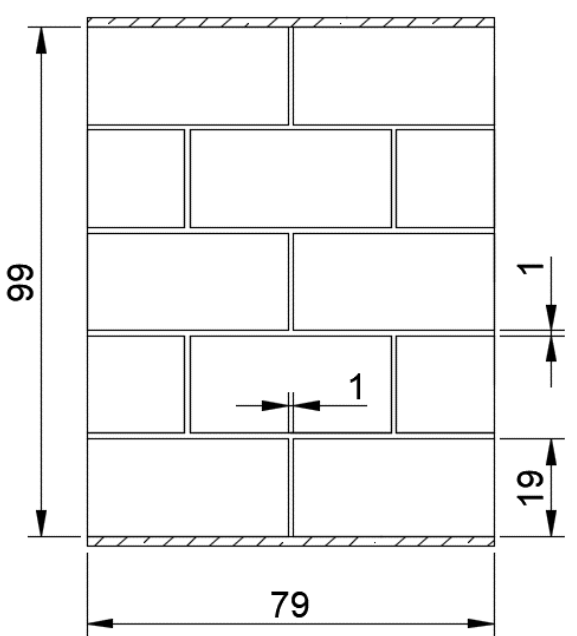

(a)

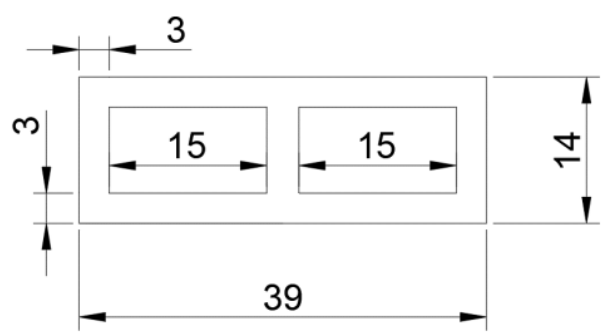

(b) 
Figura 2 - Malha utilizada nos blocos de concreto

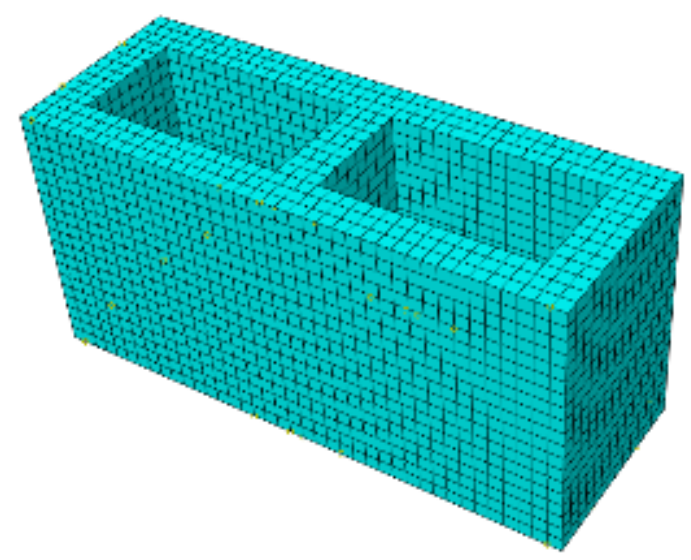

Figura 3 - Ensaios de Dupim (2019): paredes expostas ao fogo em uma e em ambas as faces

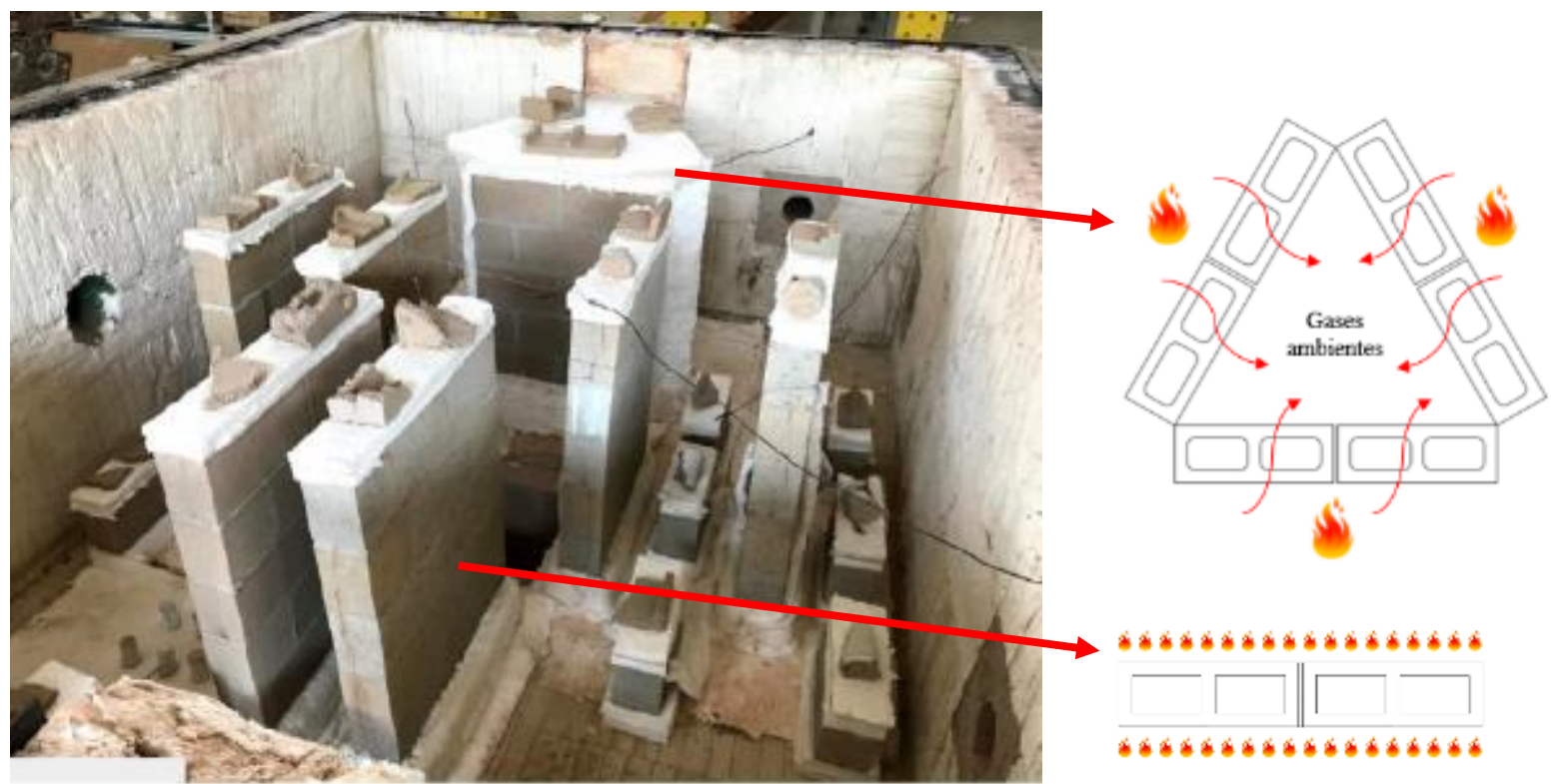

\section{Interior dos blocos}

Para a transferência de calor no interior da alvenaria, a estratégia de discretizar os vazios dos blocos e atribuir um material com propriedades térmicas equivalentes, ou mesmo a utilização de ferramentas numéricas que consideram a interação fluido-estrutura, tem sido empregada com sucesso em análises térmicas, tal como apresentado em Rodovalho (2018). No entanto, essa abordagem acaba resultando num considerável acréscimo de elementos finitos no modelo e, consequentemente, num maior tempo de processamento.

Visando reduzir o esforço computacional e o tempo de análise, é aqui proposta uma estratégia numérica alternativa, na qual a discretização dos vazios dos blocos é substituída pela atribuição de uma curva de elevação da temperatura às superfícies internas dos vazios. Por depender da geometria dos blocos e de seu material, foram realizados ensaios experimentais com blocos do mesmo lote dos utilizados em Dupim (2019) para a obtenção dessas curvas. Os ensaios foram conduzidos em um forno alocado nas dependências do Departamento de Engenharia de Estruturas da EESC/USP, alimentado a gás natural e capaz de reproduzir com considerável precisão o incêndio padrão da ISO 834 (INTERNANTIONAL..., 1999).

Antes da execução do ensaio, os furos dos blocos foram isolados termicamente por meio de mantas de fibra cerâmica posicionadas em suas faces superior e inferior. Para simular o caso de incêndio atuando em uma única face da parede, a mesma manta foi utilizada como proteção das demais faces do bloco não expostas ao 
fogo. A curva representativa da evolução da temperatura no interior da parede foi então obtida por meio de cabos termopares do tipo K posicionados nos vazios dos blocos, conforme apresentado na Figura 4.

A Figura 5 apresenta os resultados obtidos nos ensaios dos blocos em cada condição de exposição ao fogo, os quais foram utilizados como parâmetros de entrada no modelo numérico. Por sua vez, a Figura 6 apresenta, de forma esquemática, as condições de contorno aplicadas ao modelo numérico em ambos os casos aqui estudados, ou seja, com fogo atuando em uma ou em ambas as faces da alvenaria.

\section{Mecanismos de transferência de calor}

Os mecanismos de transferência de calor ao longo da espessura da parede estão indicados na Figura 7, os quais foram devidamente incluídos no modelo numérico. Dessa forma, a transferência de calor nas faces exposta e não exposta ao fogo foi considerada por convecção e por radiação, bem como nos furos internos dos blocos. Ao longo dos septos longitudinais e transversais dos blocos, bem como das juntas, se considera transferência de calor apenas por condução.

Os valores dos coeficientes de convecção $(h)$ e emissividade $(\varepsilon)$ foram adotados com base no Eurocode 2 (EUROPEAN..., 2004a, 2004b) e nos trabalhos de Santos et al. (2017) e Rodovalho (2018). A Figura 8 indica os valores utilizados para a validação do modelo em cada face (exposta e não exposta) da parede e no interior dos blocos.

\section{Figura 4 - Ensaios para a obtenção das curvas temperatura-tempo nos vazados dos blocos}

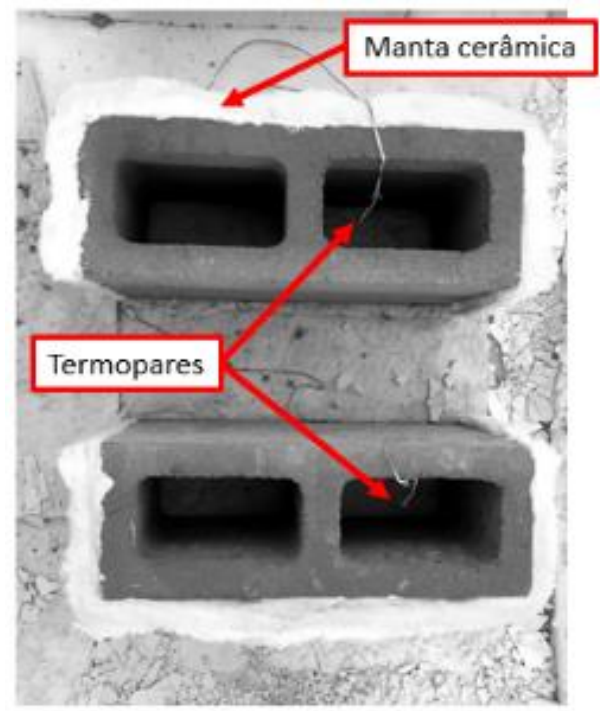

(a) Fogo atuando em uma face

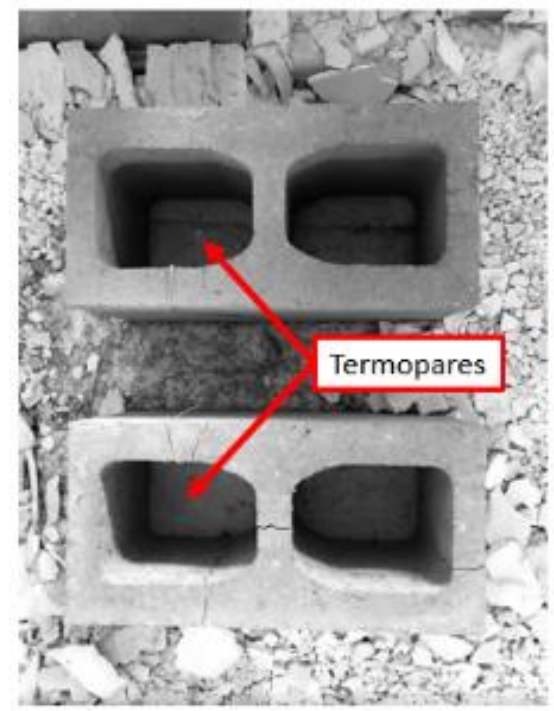

(b) Fogo atuando em ambas as faces

Figura 5 - Elevação de temperatura $\left({ }^{\circ} \mathrm{C}\right)$ ao longo do tempo $(\mathrm{min})$ medidas pelos termopares no interior dos blocos

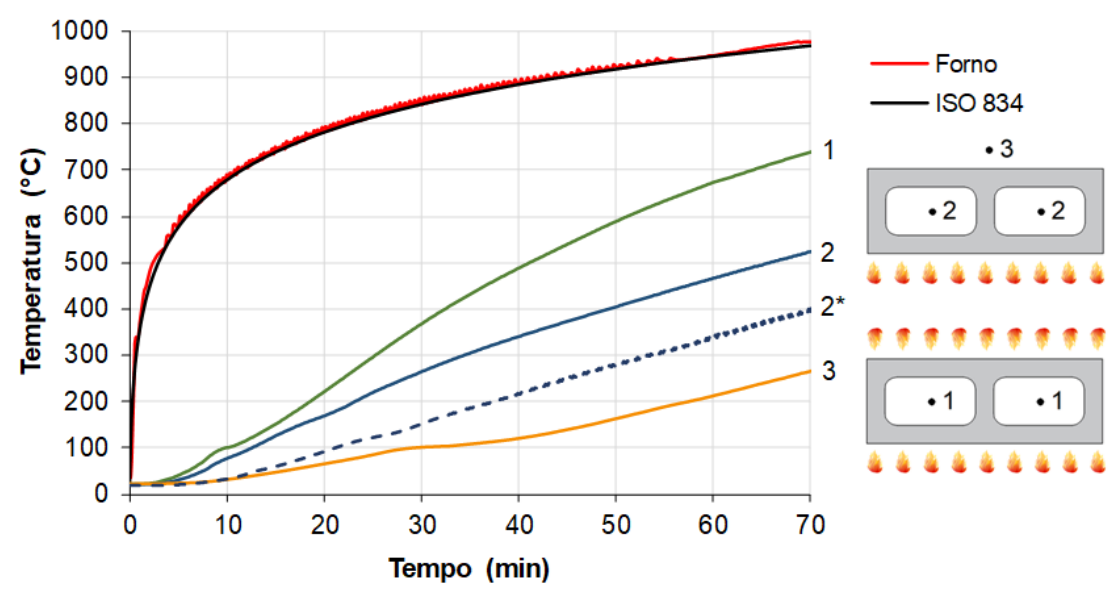

72 Carvalho, P. R. de O.; Leal, D. F.; Munair Neto, J. 
Figura 6 - Condições de contorno consideradas nas análises numéricas

(a) Fogo em uma única face: Curva 3 da Figura 5 - Dupim (2019)

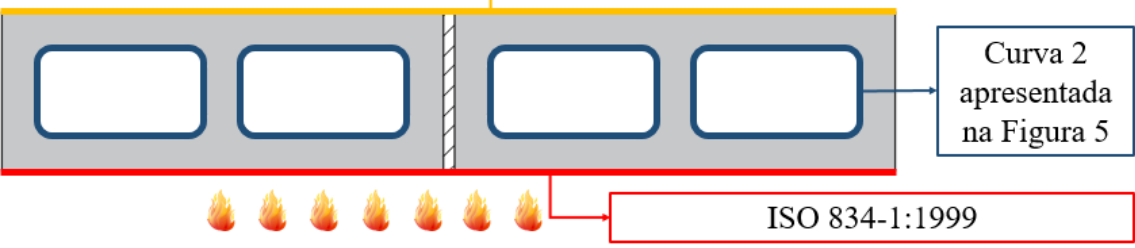

(b) Fogo em ambas as faces:

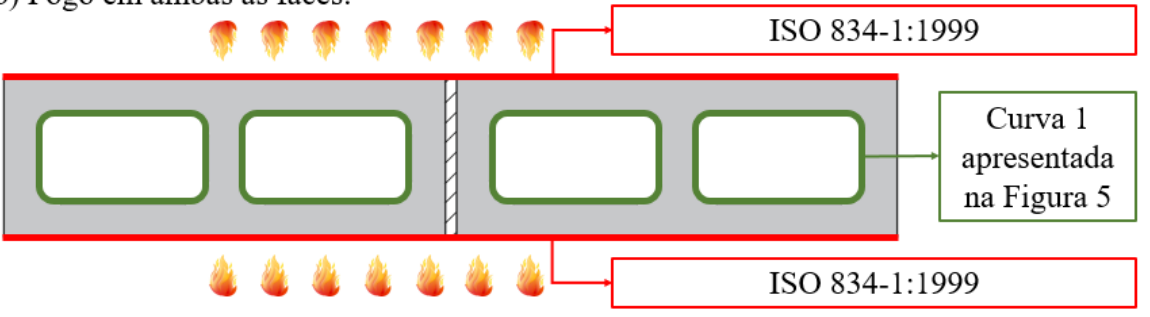

Figura 7 - Transferência de calor ao longo da espessura da alvenaria

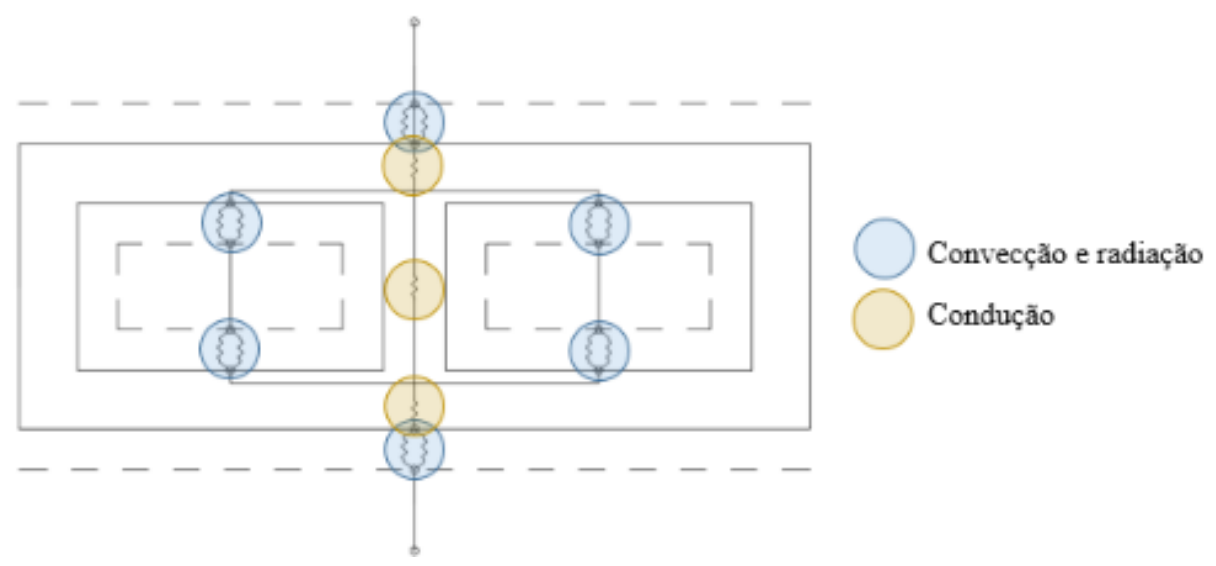

Figura 8 - Indicação dos coeficientes de convecção $\left(W /\left(m^{2} K\right)\right.$ e emissividade considerados

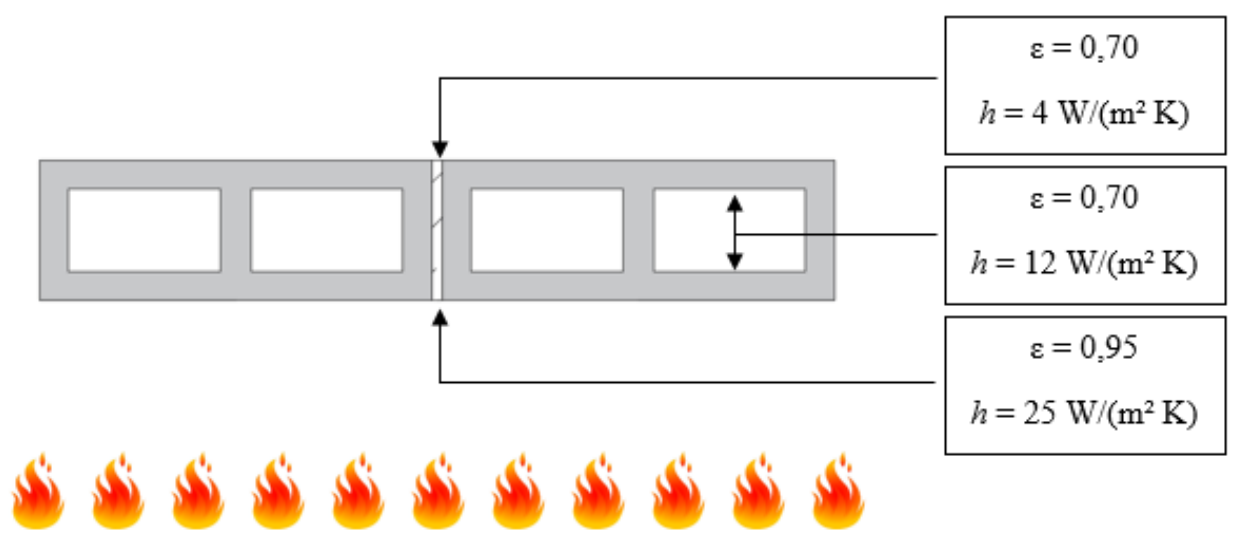

\section{Propriedades dos materiais}

Os dados de entrada do modelo se baseiam em três propriedades: massa específica, calor específico e condutividade térmica. Existe grande variação, principalmente dos dois últimos parâmetros, em função da temperatura, conforme se verifica nas prescrições do Eurocode 6 (EUROPEAN..., 2005a, 2005b), do 
Eurocode 2 (EUROPEAN..., 2004a, 2004b) e da NBR 15200 (ABNT, 2012), o que dificulta a calibração de modelos numéricos sem a execução de ensaios específicos.

Para a alvenaria estrutural em situação de incêndio não existe norma brasileira que padronize as propriedades térmicas dos materiais. Além disso, a utilização direta dos parâmetros fornecidos por normas estrangeiras implica o risco de se considerarem propriedades térmicas não representativas dos materiais empregados no Brasil. Dessa forma, optou-se por calibrar a condutividade térmica e o calor específico dentro dos limites existentes nas normas europeias para estruturas de concreto e de alvenaria estrutural, porém se tomando como base de comparação os resultados experimentais de Dupim (2019).

As calibrações para a condutividade térmica e para o calor específico que conduziram aos melhores resultados na validação do modelo térmico são apresentadas nas Figuras 9 e 10.

Como visualizado na Figura 9, a calibração do modelo ficou entre os limites definidos pelo Eurocode 2, de estruturas de concreto, e pelo Eurocode 6, de alvenaria estrutural. O pico do calor específico do modelo numérico corresponde a 12,5\% do pico do Eurocode 6 (EUROPEAN..., 2005a, 2005b), sendo 57\% maior que o valor do Eurocode 2 (EUROPEAN..., 2004a, 2004b).

Figura 9 - Calor específico ( $/ \mathrm{kg} \mathrm{K}$ ) do concreto calibrado para o modelo térmico em função da temperatura $\left({ }^{\circ} \mathrm{C}\right)$

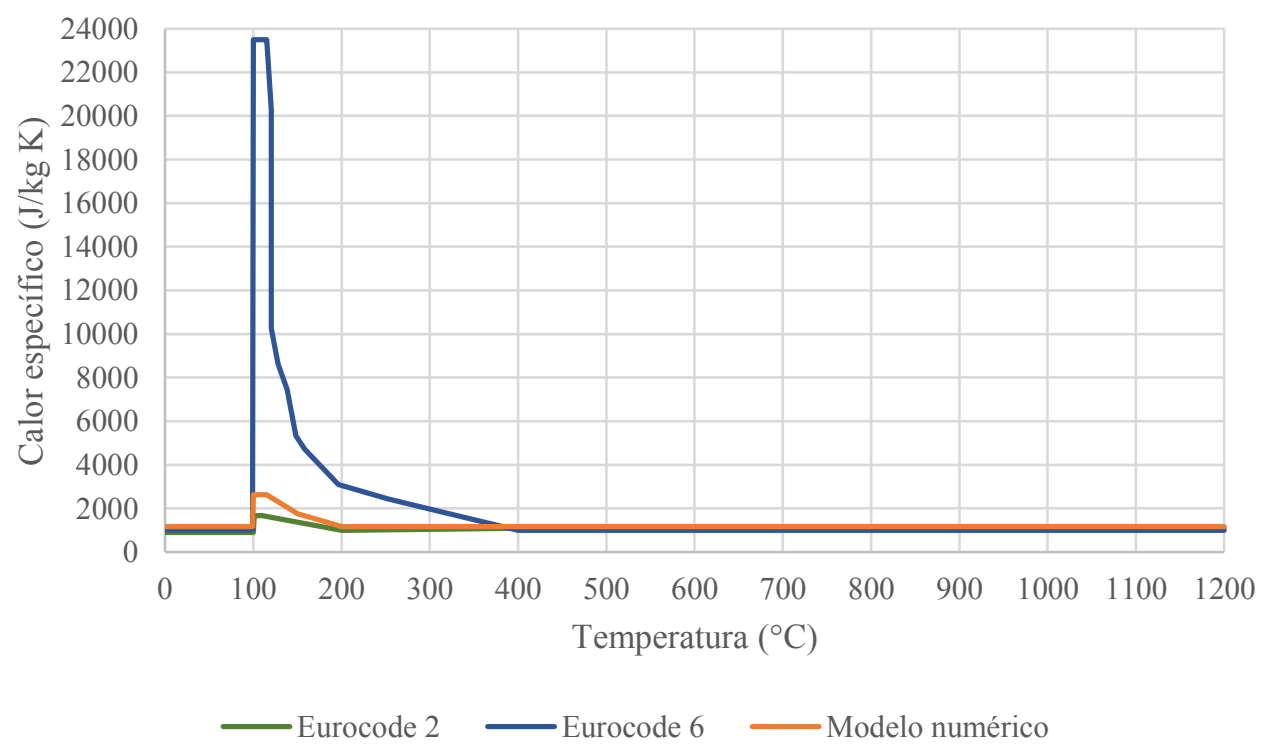

Figura 10 - Condutividade térmica $(\mathrm{W} / \mathrm{m} \mathrm{K})$ do concreto calibrada para o modelo térmico em função da temperatura $\left({ }^{\circ} \mathrm{C}\right)$

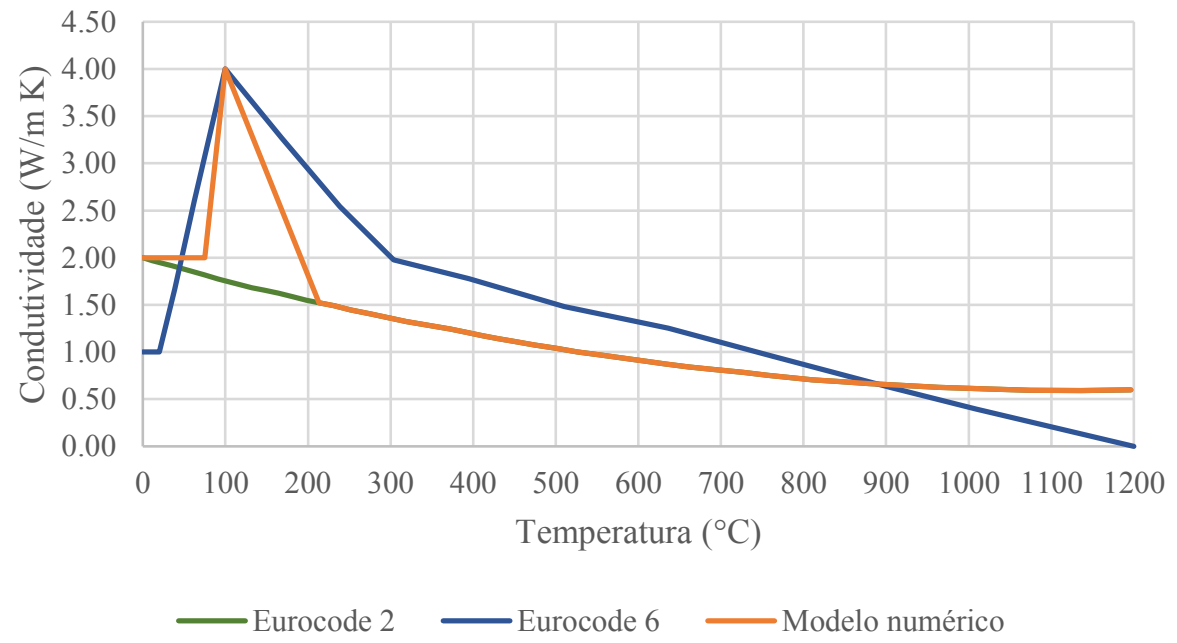

74 Carvalho, P. R. de O.; Leal, D. F.; Munair Neto, J. 
A calibração da condutividade térmica para o modelo numérico buscou seguir o Eurocode $6 \mathrm{em}$ temperaturas de até $100{ }^{\circ} \mathrm{C}$ e, posteriormente, seguiu a curva do Eurocode 2. Essa estratégia foi adotada para uma melhor adequação à condição de umidade dos blocos, superior aos valores estabelecidos no Eurocode 2. Para a argamassa de assentamento foram utilizados valores experimentais obtidos por Rosemann (2011) referentes às propriedades citadas anteriormente. O gráfico dessas propriedades é mostrado na Figura 11.

Para a massa específica de ambos os materiais foram utilizadas as Equações 1, 2, 3 e 4, a seguir, as quais estão presentes no Eurocode 2. Os valores de massa específica à temperatura ambiente foram obtidos nos trabalhos de Rosemann (2011), com valor igual a $2.100 \mathrm{~kg} / \mathrm{m}$ para a argamassa, e de Dupim (2019), para o bloco de concreto, com valor igual a $2.385 \mathrm{~kg} / \mathrm{m}$.

$$
\begin{aligned}
& \rho(\theta)=\rho\left(20^{\circ} C\right) ; 20^{\circ} C \leq \theta \leq 115^{\circ} C \\
& \rho(\theta)=\rho\left(20^{\circ} C\right) \cdot\left[1-0,02 \cdot \frac{\theta-115}{85}\right] ; 115^{\circ} C<\theta \leq 200^{\circ} C \\
& \rho(\theta)=\rho\left(20^{\circ} C\right) \cdot\left[0,98-0,03 \cdot \frac{\theta-200}{200}\right] ; 200^{\circ} C<\theta \leq 400^{\circ} C \\
& \rho(\theta)=\rho\left(20^{\circ} C\right) \cdot\left[0,95-0,07 \cdot \frac{\theta-400}{800}\right] ; 400^{\circ} C<\theta \leq 1200^{\circ} C
\end{aligned}
$$

\section{Resultados e discussões}

Os modelos numéricos desenvolvidos foram utilizados para a análise térmica das pequenas paredes submetidas às duas condições apresentadas em Dupim (2019), ou seja, com exposição ao fogo em uma ou em ambas as faces. Dessa forma, o comportamento térmico da alvenaria em situação de incêndio é aqui avaliado para o caso de paredes que atuam como elementos de compartimentação e em situações em que ela não agregaria essa função. Além disso, foram realizadas duas análises paramétricas complementares, relativas ao aumento da espessura da parede $(19 \mathrm{~cm})$ e ao uso das propriedades térmicas do Eurocode 2 (EUROPEAN..., 2004a, 2004b) e do Eurocode 6 (EUROPEAN..., 2005a, 2005b).

\section{Fogo em uma face}

A Figura 12 apresenta os resultados da elevação da temperatura ao longo da espessura da parede, onde as linhas tracejadas e cheias se referem respectivamente a valores experimentais e a valores numéricos, em resposta a diferentes tempos de exposição ao incêndio padrão indicados na legenda. Os pontos de medidas experimentais foram realizados com termopares posicionados a distâncias de $5 \mathrm{~mm}, 20 \mathrm{~mm}, 120 \mathrm{~mm}$ e 135 $\mathrm{mm}$ da face exposta ao fogo.

Para os pontos citados a Tabela 1 indica temperaturas experimentais, mínima e máxima, assim como obtidas numericamente. Adicionalmente, indica a diferença de temperatura nos casos em que o modelo não obteve resultados dentro do intervalo experimental.

\section{Figura 11 - Calor específico ( $\mathrm{J} / \mathrm{kg} \mathrm{K})$ e condutividade térmica $(\mathrm{W} / \mathrm{m} \mathrm{K})$ da argamassa em função da} temperatura $\left({ }^{\circ} \mathrm{C}\right)$

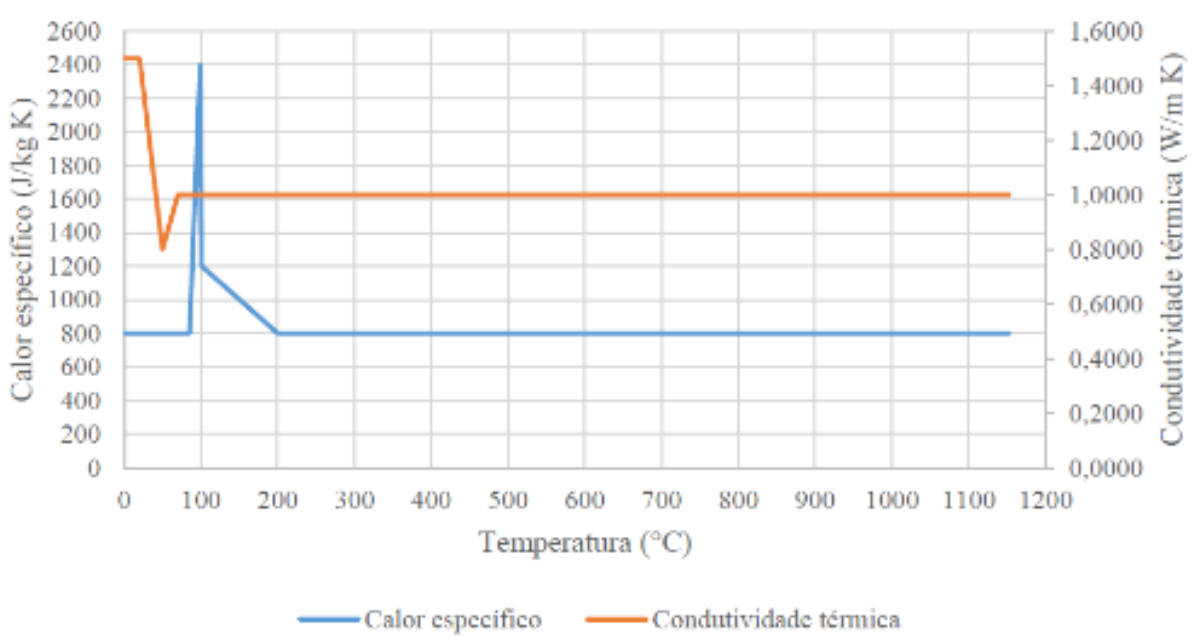

Fonte: adaptada de Rosemann (2011). 
Figura 12 - Fogo em uma face: evolução da temperatura $\left({ }^{\circ} \mathrm{C}\right)$ ao longo da espessura $(\mathrm{mm})$ da parede de acordo com os tempos de exposição indicados

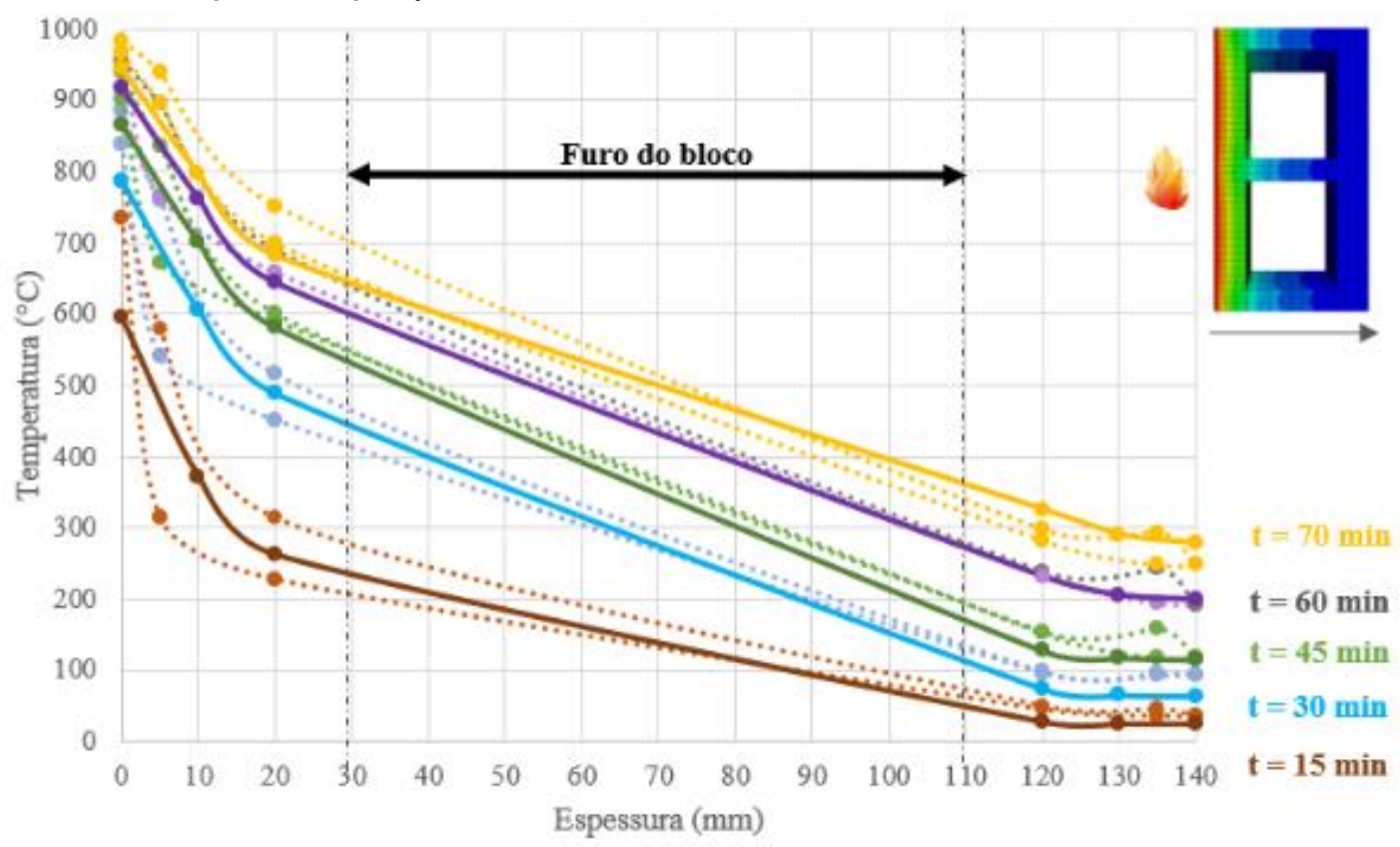

Tabela 1 - Paredes com uma face exposta ao fogo: temperaturas $\left({ }^{\circ} \mathrm{C}\right)$ obtidas na análise numérica em comparação com os resultados experimentais de Dupim (2019)

\begin{tabular}{|c|c|c|c|c|c|}
\hline $\begin{array}{l}\text { Distância à } \\
\text { face exposta } \\
(\mathbf{m m})\end{array}$ & $\begin{array}{c}\text { Tempo de } \\
\text { incêndio } \\
\text { (min) }\end{array}$ & \multicolumn{2}{|c|}{$\begin{array}{c}\text { Limites } \\
\text { experimentais } \\
\left({ }^{\circ} \mathrm{C}\right)\end{array}$} & $\begin{array}{c}\text { Modelo } \\
\text { numérico } \\
\left({ }^{\circ} \mathrm{C}\right)\end{array}$ & $\begin{array}{c}\text { Diferença entre } \\
\text { numérico e } \\
\text { experimental }\left({ }^{\circ} \mathrm{C}\right)\end{array}$ \\
\hline \multirow{5}{*}{5} & 15 & 314,0 & 580,3 & 483,6 & - \\
\hline & 30 & 540,0 & 758,5 & 697,3 & - \\
\hline & 45 & 671,0 & 835,3 & 783,9 & - \\
\hline & 60 & 764,0 & 895,9 & 839,8 & - \\
\hline & 70 & 825,0 & 938,7 & 870,2 & - \\
\hline \multirow{5}{*}{20} & 15 & 228,0 & 314,8 & 263,0 & - \\
\hline & 30 & 452,0 & 515,4 & 489,1 & - \\
\hline & 45 & 599,9 & 671,0 & 581,3 & $-18,6$ \\
\hline & 60 & 658,0 & 691,0 & 643,8 & $-14,2$ \\
\hline & 70 & 700,0 & 752,0 & 681,8 & $-18,2$ \\
\hline \multirow{5}{*}{120} & 15 & 46,0 & 51,1 & 28,8 & $-17,2$ \\
\hline & 30 & 97,1 & 98,0 & 74,0 & $-23,1$ \\
\hline & 45 & 152,6 & 153,0 & 128,1 & $-24,5$ \\
\hline & 60 & 232,5 & 239,0 & 232,3 & - \\
\hline & 70 & 282,9 & 297,0 & 326,5 & 29,5 \\
\hline \multirow{5}{*}{135} & 15 & 37,0 & 47,4 & 26,1 & $-10,9$ \\
\hline & 30 & 93,0 & 97,6 & 64,4 & $-28,6$ \\
\hline & 45 & 118,0 & 158,1 & 117,0 & $-1,0$ \\
\hline & 60 & 194,0 & 243,0 & 202,9 & - \\
\hline & 70 & 249,0 & 294,1 & 284,9 & - \\
\hline
\end{tabular}

Apesar dos desvios indicados, percebe-se boa correlação do modelo numérico com os resultados médios experimentais. As diferenças encontradas para os pontos a $120 \mathrm{~mm}$ e a $135 \mathrm{~mm}$ podem ser consideradas pequenas em resposta às temperaturas atingidas no ambiente aquecido, dado que as maiores diferenças obtidas entre os valores experimentais e numéricos foram inferiores a $30{ }^{\circ} \mathrm{C}$. Ademais, conforme as medidas experimentais se distanciaram da face exposta ao fogo, o intervalo entre os limites foi reduzido, conferindo 
maior nível de precisão aos resultados numéricos. Verifica-se assim um bom comportamento do modelo numérico em comparação aos resultados experimentais.

A elevação da temperatura em alguns pontos da seção é apresentada na Figura 13 em função do tempo de exposição ao fogo, onde as linhas tracejadas representam os resultados experimentais médios e as linhas cheias representam os resultados numéricos.

Verifica-se que as curvas numéricas referentes aos pontos avaliados apresentam tendência semelhante às respectivas curvas experimentais, em que, por influência dos vazios internos dos blocos, a face não exposta ao fogo apresenta taxas de elevação da temperatura bem menores quando comparada aos pontos mais próximos da face de atuação do incêndio simulado.

Assim como relatado em Lopes et al. (2018), observa-se a formação de patamares aos $100{ }^{\circ} \mathrm{C}$, nos quais há pouca variação de temperatura por um período, retardando o aquecimento ao longo da seção da parede. Segundo Al Nahhas et al. (2007), tal fenômeno ocorre devido à umidade presente no concreto, sendo a duração desses patamares variável em função da distância do ponto analisado em relação à face exposta ao fogo.

Os resultados numéricos mostram ainda que o aquecimento da região central dos septos transversais dos blocos (ponto a $70 \mathrm{~mm}$ da face exposta) ocorre de forma mais lenta, visto que a presença de umidade tende a reduzir o fluxo de calor através do concreto. Portanto, constata-se que o caminho preferencial para o fluxo de calor ao longo da espessura da alvenaria é através dos furos dos blocos em vez de seus septos transversais.

Em relação ao critério de isolamento térmico, a Tabela 2 indica os valores obtidos experimental e numericamente. Para os valores numéricos foram inseridos dois resultados, um deles referente ao aumento da temperatura no valor máximo de $180{ }^{\circ} \mathrm{C}$, e outro pela média das temperaturas na superfície da parede inferior a $140{ }^{\circ} \mathrm{C}$, sendo ambos os casos verificados na superfície não exposta ao fogo. Verifica-se grande proximidade das temperaturas na face oposta ao fogo entre os valores experimental e numérico. Para a resistência ao fogo segundo o critério de isolamento térmico, a variação foi de $2 \mathrm{~min}$.

Figura 13 - Fogo em uma face: elevação da temperatura $\left({ }^{\circ} \mathrm{C}\right)$ em função do tempo $(\min )$ de exposição

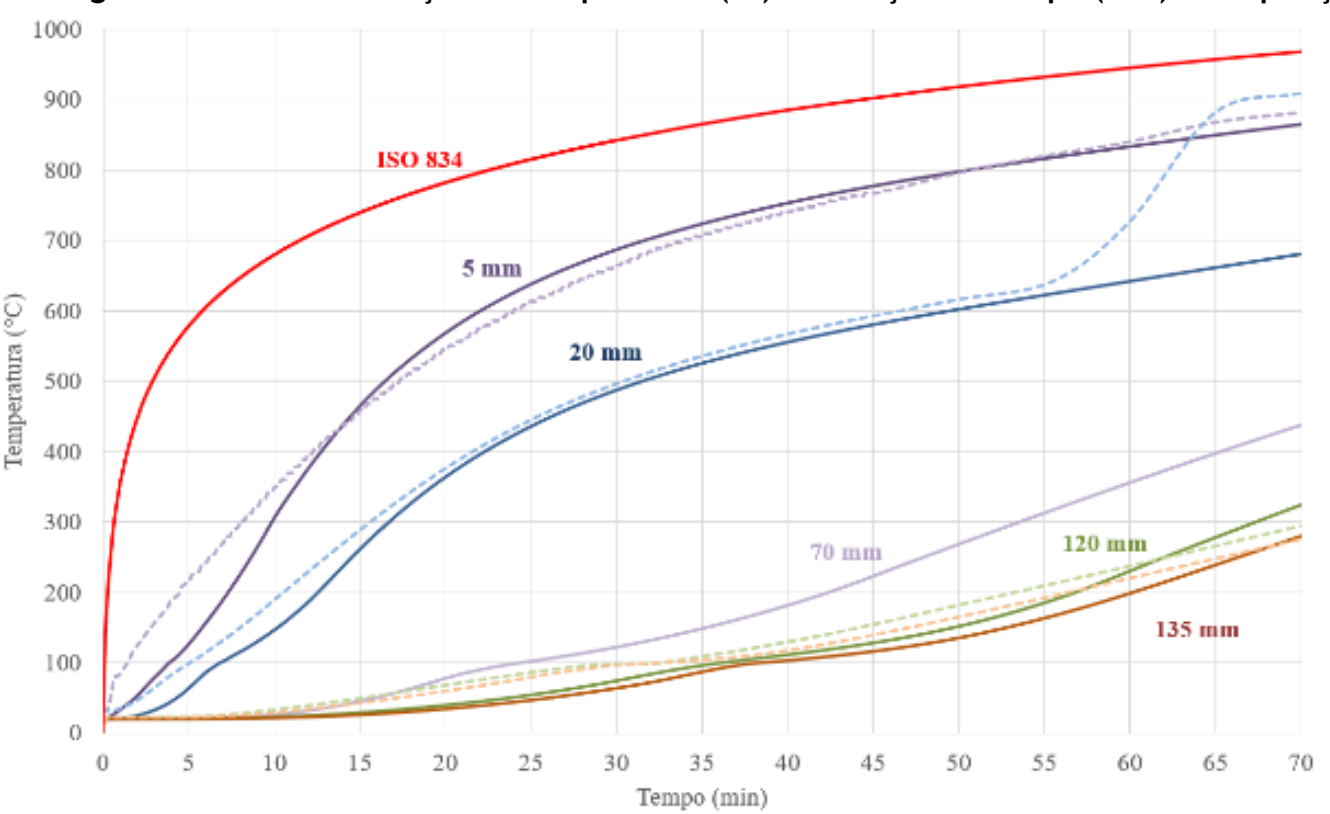

Tabela 2 - Comparação dos resultados numéricos quanto ao critério de isolamento térmico (min)

\begin{tabular}{c|c|c}
\hline \multirow{2}{*}{$\begin{array}{c}\text { Experimental } \\
\text { (valor máximo) }\end{array}$} & \multicolumn{2}{|c}{ Numérico } \\
\cline { 2 - 3 } & Valor máximo & Valor médio \\
\hline 62 & 60 & 52 \\
\hline
\end{tabular}


A importância da avaliação de elementos verticais de vedação (tais como paredes de alvenaria) quanto a sua capacidade de isolamento térmico está expressa na NBR 15575-4 (ABNT, 2013), a qual estabelece como requisito a ser atendido que esses elementos dificultem a propagação do incêndio de um ambiente para outro dentro da edificação. Além disso, as normas exigem que algumas paredes das edificações devem acumular também a função de compartimentação, tais como as que definem o contorno das caixas de escadas e elevadores de segurança, paredes externas, ou que separam unidades habitacionais e aquelas que fazem divisa com as áreas comuns nos edifícios multifamiliares.

Nesse contexto, considerando os tempos requeridos de resistência ao fogo (TRRF) especificados na NBR 14432 (ABNT, 2001) e na IT 08 (CORPO..., 2011), os resultados experimentais e numéricos apresentados na Tabela 2 apontam que edifícios de alvenaria estrutural residenciais com mais de $23 \mathrm{~m}$ de altura construídos com blocos de concreto semelhantes aos da Figura 1 podem apresentar problemas em relação ao critério de isolamento térmico em situação de incêndio. Sendo assim, destaca-se a necessidade de se estudarem formas de proteção das paredes contra o fogo, tais como a utilização de materiais de revestimento ou de preenchimento adequados a essa finalidade.

\section{Fogo em ambas as faces}

Os resultados das análises quanto à evolução de temperatura ao longo do tempo estão apresentados na Figura 14, considerando-se os pontos a $5 \mathrm{~mm}$ e a $20 \mathrm{~mm}$ da face exposta ao fogo mais próxima. As linhas tracejadas representam os resultados médios experimentais, enquanto as linhas cheias representam os resultados numéricos.

A Tabela 3 indica os valores de temperaturas experimental e numérico obtidos para intervalos de 15 min. Analogamente ao identificado para as paredes com fogo em uma face, também se verifica boa concordância dos resultados numéricos em relação aos resultados experimentais, com variações inferiores a $42{ }^{\circ} \mathrm{C}$ dentro do intervalo estudado. Ressalta-se que as maiores diferenças encontradas entre as curvas de 5 mm na Figura 14 estão diretamente relacionadas às variações encontradas no próprio experimento, conforme se observa nos limites experimentais apresentados na Tabela 3, os quais são mais expressivos nos pontos mais próximos à superfície exposta ao fogo devido às dificuldades para a fixação dos termopares.

Figura 14 - Fogo em ambas as faces: elevação da temperatura $\left({ }^{\circ} \mathrm{C}\right)$ em função do tempo $(\min )$ de exposição

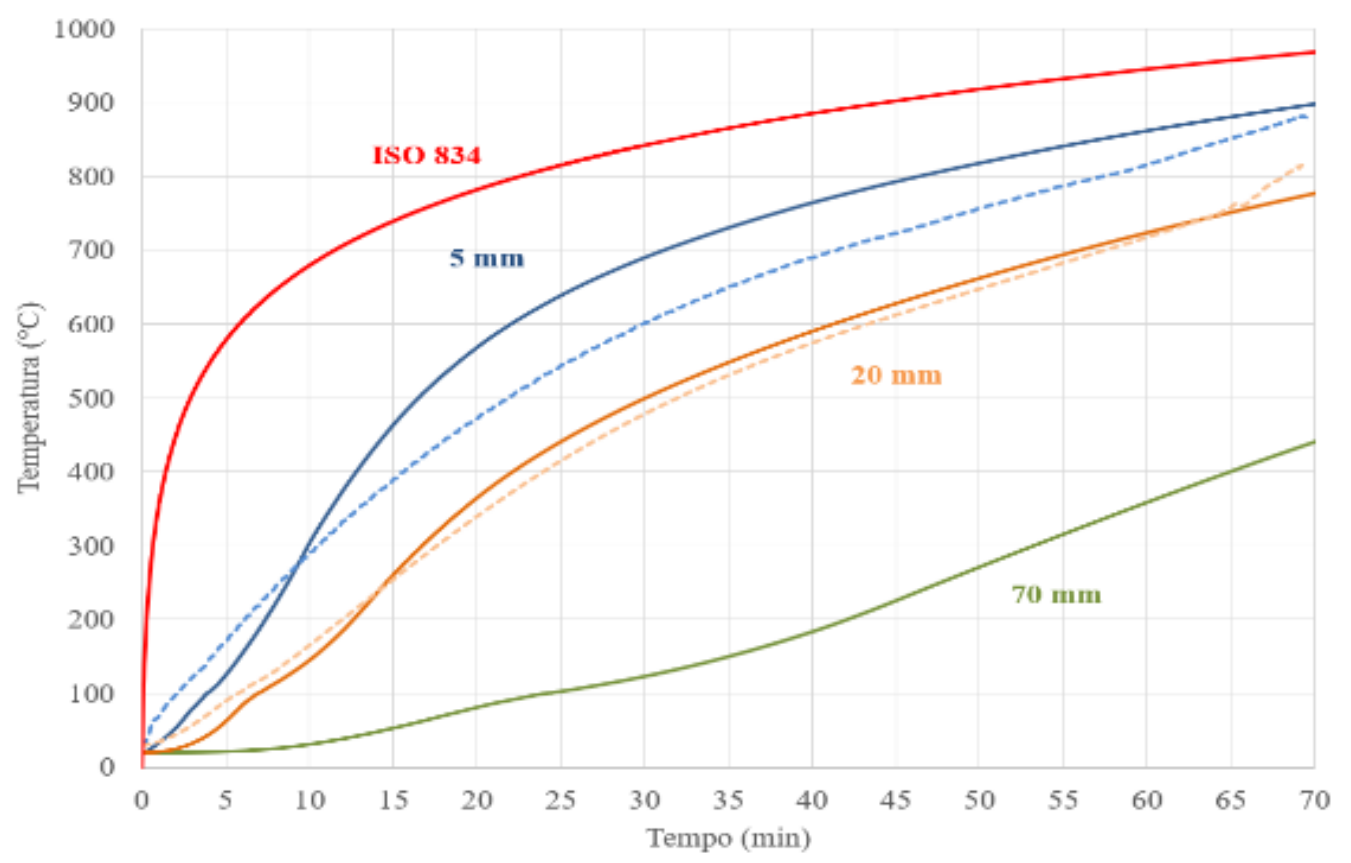

78 Carvalho, P. R. de O.; Leal, D. F.; Munair Neto, J. 
Tabela 3 - Paredes com ambas as faces expostas ao fogo: temperaturas $\left({ }^{\circ} \mathrm{C}\right)$ obtidas na análise numérica em comparação com os resultados experimentais de Dupim (2019)

\begin{tabular}{c|c|c|c|c|c}
\hline $\begin{array}{c}\text { Distância à face } \\
\text { exposta mais } \\
\text { próxima (mm) }\end{array}$ & $\begin{array}{c}\text { Tempo de } \\
\text { incêndio } \\
(\mathbf{m i n})\end{array}$ & \multicolumn{2}{|c|}{$\begin{array}{c}\text { Limites } \\
\text { experimentais } \\
\left({ }^{\mathbf{0}} \mathbf{C}\right)\end{array}$} & $\begin{array}{c}\text { Modelo } \\
\text { numérico } \\
\left({ }^{\mathbf{0}} \mathbf{C}\right)\end{array}$ & $\begin{array}{c}\text { Diferença entre } \\
\text { numérico e } \\
\text { experimental }\left({ }^{\mathbf{0}} \mathbf{C}\right)\end{array}$ \\
\hline \multirow{3}{*}{$\mathbf{5}$} & 15 & 322,0 & 453,0 & 487,6 & 34,6 \\
& 30 & 545,0 & 657,0 & 698,6 & 41,6 \\
& 45 & 674,4 & 772,0 & 790,8 & 18,8 \\
& 60 & 767,0 & 863,0 & 860,2 & - \\
& 70 & 811,0 & 918,0 & 896,5 & - \\
\hline \multirow{2}{*}{$\mathbf{2 0}$} & 15 & 235,0 & 271,0 & 266,4 & 8,1 \\
& 30 & 458,0 & 498,0 & 506,1 & $-4,8$ \\
& 45 & 594,0 & 630,0 & 625,2 & - \\
\hline
\end{tabular}

Comparando os resultados numéricos dos dois casos analisados, percebe-se que os níveis de temperatura atingidos nos pontos a $5 \mathrm{~mm}$ e a $20 \mathrm{~mm}$ da parede com fogo atuando em ambas as faces são maiores, durante toda a análise, do que os mesmos pontos da parede com apenas uma face exposta, registrando-se diferenças de até $93{ }^{\circ} \mathrm{C}$. Tal constatação já era esperada, uma vez que as diferenças nas condições de exposição impõem uma situação bem mais desfavorável para as paredes sem função de compartimentação.

Aos 60 min de exposição as temperaturas máximas atingidas nesses dois pontos ficaram entre $644{ }^{\circ} \mathrm{C}$ e 860 ${ }^{\circ} \mathrm{C}$ nas análises numéricas, o que tende a ser crítico para a capacidade resistente da alvenaria. Segundo o Eurocode 2 (EUROPEAN..., 2004a, 2004b), concretos produzidos com agregados silicosos (tal como o aqui analisado) acumulam perda de cerca de $65 \%$ a $90 \%$ em resistência à compressão entre esses níveis de temperatura, o que representa um risco à segurança das edificações em alvenaria estrutural em situação de incêndio. Nesse caso, os resultados reforçam a necessidade de se considerar a proteção da alvenaria estrutural contra o fogo, sobretudo em edifícios de múltiplos andares, onde os tempos requeridos de resistência ao fogo (TRRF) são maiores, conforme definido na NBR 14432 (ABNT, 2001) e na IT 08 (CORPO..., 2011).

\section{Análise complementar 1: alteração da temperatura na face oposta}

A variação da condição de contorno na face não exposta ao fogo é aqui analisada de forma a desconsiderar a existência de gases confinados no ambiente oposto ao incêndio. Nesse caso, em vez de utilizar a curva referente ao aquecimento do espaço interno do trio de paredes do ensaio experimental de Dupim (2019) curva 3 da Figura 6 -, a temperatura do ambiente não incendiado foi considerada constante e igual a $20^{\circ} \mathrm{C}$.

A Tabela 4 indica, para ambas as configurações estudadas, as temperaturas obtidas nos pontos de medida indicados em diferentes tempos de exposição ao fogo. Verifica-se nos primeiros 60 min de incêndio que o septo longitudinal exposto ao fogo não apresenta variação quanto ao aumento de temperaturas devido à mudança da condição de contorno da face oposta. Isso significa que nos trechos iniciais de espessura da parede a predominância acerca da transferência de calor se baseia nas temperaturas da face exposta e nas propriedades dos materiais, bem como nos coeficientes de transferência de calor envolvidos.

Por outro lado, no septo longitudinal oposto ao fogo a variação de temperatura passa a ser mais significativa com o aumento do tempo de incêndio, resultando em ganho no tempo de resistência ao fogo da parede segundo o critério de isolamento térmico. Na Tabela 5 estão indicados os tempos relativos ao isolamento térmico para as duas situações analisadas.

Verifica-se ganho de 7 min a 8 min quando sem confinamento na face oposta em relação à condição de contorno considerada no ensaio de Dupim (2019). Esse resultado é coerente, uma vez que no ensaio ocorreu o confinamento de gases no espaço interno ao trio de paredes, o que eleva a temperatura mais rapidamente na face não exposta ao fogo. Embora tenha tido uma significativa variação percentual, essa diferença não resulta em ganhos importantes ao se analisarem os TRRF prescritos nas normas vigentes [NBR 14432 (ABNT, 2001) e IT 08 (CORPO..., 2011)], uma vez que o aumento do limite permitido para a altura da edificação está condicionado a um tempo de resistência ao fogo de pelo menos 90 min. Ressalta-se mais uma 
vez que a utilização de materiais de revestimento com propriedades adequadas se apresenta como uma das opções para garantir maiores ganhos de isolamento térmico da alvenaria.

\section{Análise complementar 2: variação da espessura da parede}

Para esta análise foi desconsiderado o confinamento de gases aquecidos na face oposta ao fogo, abordado no item anterior. As paredes foram analisadas considerando blocos vazados com dimensões externas de 19x19x39 cm, septos longitudinais de $30 \mathrm{~mm}$ e septos transversais de $25 \mathrm{~mm}$. Como a geometria foi alterada, a curva temperatura-tempo dos gases no interior dos furos dos blocos foi modificada com base em resultados experimentais realizados com blocos com as referidas dimensões, sendo utilizada a curva $2 *$ da Figura 6 na análise numérica. Em relação às propriedades dos materiais, foram utilizadas as mesmas dos blocos com largura de $14 \mathrm{~cm}$, bem como o coeficiente de convecção e a emissividade. A Tabela 6 indica as temperaturas obtidas para diferentes pontos de medição, de acordo com o tempo de incêndio, comparando as duas espessuras de paredes analisadas.

Verifica-se que o aquecimento da face oposta ao fogo após 90 min de exposição ao incêndio padrão se retarda em cerca de $120{ }^{\circ} \mathrm{C}$ na comparação entre as espessuras de $14 \mathrm{~cm}$ e $19 \mathrm{~cm}$. Além disso, percebe-se que o aumento de temperatura ocorre de forma mais lenta ao longo da espessura da parede de $19 \mathrm{~cm}$, aspecto que se dá, principalmente, em resposta ao aumento da espessura dos septos longitudinais dos blocos, o qual interfere tanto na transferência de calor por condução, que possui maior distância a ser percorrida, quanto na curva interna dos gases no interior dos septos. Quanto ao critério de isolamento térmico, a Tabela 7 resume os resultados obtidos numericamente.

O critério de isolamento térmico é atingido aos 59 min para parede com espessura de $14 \mathrm{~cm}$, e aos 80 min para espessura de $19 \mathrm{~cm}$. Ocorre um ganho de $21 \mathrm{~min}$ diante do aumento da espessura da parede.

Tabela 4 - Temperaturas $\left({ }^{\circ} \mathrm{C}\right)$ atingidas ao longo da espessura $(\mathrm{mm})$ da parede para diferentes configurações da face oposta ao fogo

\begin{tabular}{c|c|c|c|c|c|c}
\hline \multirow{2}{*}{$\begin{array}{c}\text { Tempo de } \\
\text { exposição (min) }\end{array}$} & \multirow{2}{*}{ Gases - face oposta } & \multicolumn{5}{|c}{ Distância da face exposta (mm) } \\
\cline { 3 - 7 } $\mathbf{4} 15$ & Com confinamento & 597,5 & 228,7 & 42,5 & 34,5 & 26,1 \\
& Sem confinamento & 597,5 & 228,7 & 42,5 & 34,0 & 25,6 \\
& Diferença & 0,0 & 0,0 & 0,0 & 0,5 & 0,5 \\
\hline \multirow{3}{*}{$\mathbf{3 0}$} & Com confinamento & 788,0 & 414,5 & 116,3 & 87,4 & 68,7 \\
& Sem confinamento & 788,0 & 414,5 & 116,3 & 84,3 & 59,4 \\
& Diferença & 0,0 & 0,0 & 0,0 & 3,1 & 9,3 \\
\hline \multirow{2}{*}{45} & Com confinamento & 866,1 & 492,6 & 211,6 & 147,4 & 115,7 \\
& Sem confinamento & 866,1 & 492,6 & 209,8 & 140,0 & 106,2 \\
& Diferença & 0,0 & 0,0 & 1,8 & 7,4 & 9,5 \\
\hline \multirow{2}{*}{$\mathbf{6 0}$} & Com confinamento & 916,6 & 552,8 & 344,8 & 281,6 & 198,4 \\
& Sem confinamento & 916,6 & 552,8 & 342,6 & 256,2 & 165,2 \\
& Diferença & 0,0 & 0,0 & 2,2 & 25,4 & 33,2 \\
\hline
\end{tabular}

Tabela 5 - Resistência ao fogo (min) relativa ao critério de isolamento térmico: resultados numéricos considerando variações na condição de contorno da face oposta ao fogo

\begin{tabular}{c|c|c|c}
\hline \multicolumn{2}{c|}{ Valor médio $\left(\right.$ variação $\left.=\mathbf{1 4 0}^{\mathbf{}} \mathbf{C}\right)$} & \multicolumn{2}{c}{ Valor máximo $\left(\right.$ variação $\left.=\mathbf{1 8 0}^{\circ} \mathbf{C}\right)$} \\
\hline $\begin{array}{c}\text { Com } \\
\text { confinamento }\end{array}$ & Sem confinamento & $\begin{array}{c}\text { Com } \\
\text { confinamento }\end{array}$ & Sem confinamento \\
\hline 52 & 59 & 60 & 68 \\
\hline
\end{tabular}


Tabela 6 - Temperaturas $\left({ }^{\circ} \mathrm{C}\right)$ atingidas em relação à distância $(\mathrm{cm})$ da face exposta em função do tempo para diferentes espessuras

\begin{tabular}{c|c|c|c|c|c|c}
\hline \multirow{2}{*}{$\begin{array}{c}\text { Tempo de } \\
\text { incêndio } \\
(\mathbf{m i n})\end{array}$} & $\begin{array}{c}\text { Espessura } \\
(\mathbf{c m})\end{array}$ & $\begin{array}{c}\text { Face } \\
\text { exposta }\end{array}$ & $\begin{array}{c}\text { Septo interno } \\
- \text { oposto à } \\
\text { face exposta }\end{array}$ & Meio & $\begin{array}{c}\text { Septo interno }- \\
\text { oposto à face } \\
\text { oposta }\end{array}$ & $\begin{array}{c}\text { Face } \\
\text { oposta }\end{array}$ \\
\cline { 3 - 7 } $\mathbf{1 5}$ & 14 & 597,5 & 228,7 & 42,5 & 34,0 & 25,6 \\
& 19 & 583,0 & 157,7 & 33,0 & 23,9 & 20,2 \\
& Diferença & 14,5 & 71,0 & 9,5 & 10,1 & 5,4 \\
\hline \multirow{3}{*}{$\mathbf{3 0}$} & 14 & 788,0 & 414,5 & 116,3 & 84,3 & 59,4 \\
& 19 & 780,1 & 341,5 & 90,3 & 45,6 & 22,8 \\
& Diferença & 7,9 & 73,0 & 26,0 & 38,7 & 36,6 \\
\hline \multirow{2}{*}{$\mathbf{4 5}$} & 14 & 866,1 & 492,6 & 209,8 & 140,0 & 106,2 \\
& 19 & 862,0 & 415,0 & 149,5 & 85,8 & 52,8 \\
& Diferença & 4,1 & 77,6 & 60,3 & 54,2 & 53,4 \\
\hline \multirow{2}{*}{$\mathbf{6 0}$} & 14 & 916,6 & 552,8 & 342,6 & 256,2 & 165,2 \\
& 19 & 914,5 & 469,7 & 235,1 & 120,4 & 90,0 \\
& Diferença & 2,1 & 83,1 & 107,5 & 135,8 & 75,2 \\
\hline \multirow{2}{*}{$\mathbf{9 0}$} & 14 & 986,4 & 676,1 & 580,7 & 528,3 & 310,3 \\
& 19 & 983,5 & 576,0 & 439,5 & 335,3 & 190,7 \\
& Diferença & 2,9 & 100,1 & 141,2 & 193,0 & 119,6 \\
\hline
\end{tabular}

Tabela 7 - Resistência ao fogo (min) relativa ao critério de isolamento térmico: comparação quanto à variação da espessura da parede

\begin{tabular}{c|c|c|c}
\hline \multicolumn{2}{c|}{ Valor médio (variação $\left.=\mathbf{1 4 0}{ }^{\mathbf{0}} \mathrm{C}\right)$} & \multicolumn{2}{c}{ Valor máximo $\left(\right.$ variação $\left.=\mathbf{1 8 0}{ }^{\mathbf{0}} \mathbf{C}\right)$} \\
\hline $\mathbf{e}=\mathbf{1 4} \mathbf{~ c m}$ & $\mathbf{e}=\mathbf{1 9} \mathbf{~ c m}$ & $\mathbf{e}=\mathbf{1 4} \mathbf{~ c m}$ & $\mathbf{e}=\mathbf{1 9} \mathbf{~ c m}$ \\
\hline 59 & 80 & 68 & 91 \\
\hline
\end{tabular}

\section{Análise complementar 3: variação das propriedades térmicas dos materiais}

Neste tópico são utilizados os parâmetros térmicos existentes no Eurocode 2 (EUROPEAN..., 2004a, 2004b) e no Eurocode 6 (EUROPEAN..., 2005a, 2005b) em comparação com os valores calibrados anteriormente a partir dos resultados experimentais (Figuras 9 e 10). Neste caso foi desconsiderado o confinamento de gases na face oposta ao fogo. A Figura 15 indica a evolução de temperaturas ao longo da parede com espessura de $14 \mathrm{~cm}$ para cada situação. As linhas cheias se referem ao modelo calibrado, as pontilhadas se referem às curvas do Eurocode 2 (EUROPEAN..., 2004a, 2004b), e as tracejadas se referem às curvas do Eurocode 6 (EUROPEAN..., 2005a, 2005b).

As Figuras 16 e 17 indicam a evolução da temperatura em função do tempo de exposição ao fogo, considerando-se análises numéricas realizadas com as propriedades térmicas calibradas com os resultados experimentais de Dupim (2019) em comparação com as propriedades térmicas especificadas no Eurocode 2 (EUROPEAN..., 2004a, 2004b) e no Eurocode 6 (EUROPEAN..., 2005a, 2005b). Os nomes D0 a D14 constantes na legenda se referem à distância dos pontos de medição da temperatura em relação à face exposta ao fogo (por exemplo, D2 corresponde a um ponto localizado no interior do bloco distante $2 \mathrm{~cm}$ da face exposta).

As Figuras 15 e 16 mostram grande proximidade entre os resultados numéricos do Eurocode 2 com os das análises com as propriedades térmicas calibradas experimentalmente, tendo as curvas apresentado tendências de evolução de temperatura semelhantes em todos os pontos analisados. Por outro lado, na Figura 17 se verifica a ocorrência de extensos patamares aos $100{ }^{\circ} \mathrm{C}$ nas curvas do Eurocode 6 , os quais apresentam intervalos de duração maiores conforme se aumenta a distância em relação à face exposta ao fogo. Tal fato foi também verificado nos experimentos de Dupim (2019), porém com menor intensidade. Com isso, notase, nas curvas provenientes dos parâmetros do Eurocode 6 um grande atraso para a evolução das temperaturas em função do tempo, aspecto atrelado principalmente ao elevado calor específico à temperatura de $100{ }^{\circ} \mathrm{C}$, o qual é cerca de 11 vezes maior que o valor máximo fornecido pelo Eurocode 2 (Figura 9). Esse comportamento se difere rigorosamente do verificado experimentalmente no trabalho de Dupim (2019). 
Figura 15 - Temperaturas $\left({ }^{\circ} \mathrm{C}\right)$ ao longo da espessura $(\mathrm{mm})$ da parede: propriedades térmicas calibradas com base em ensaios em comparação com os Eurocodes 2 e 6

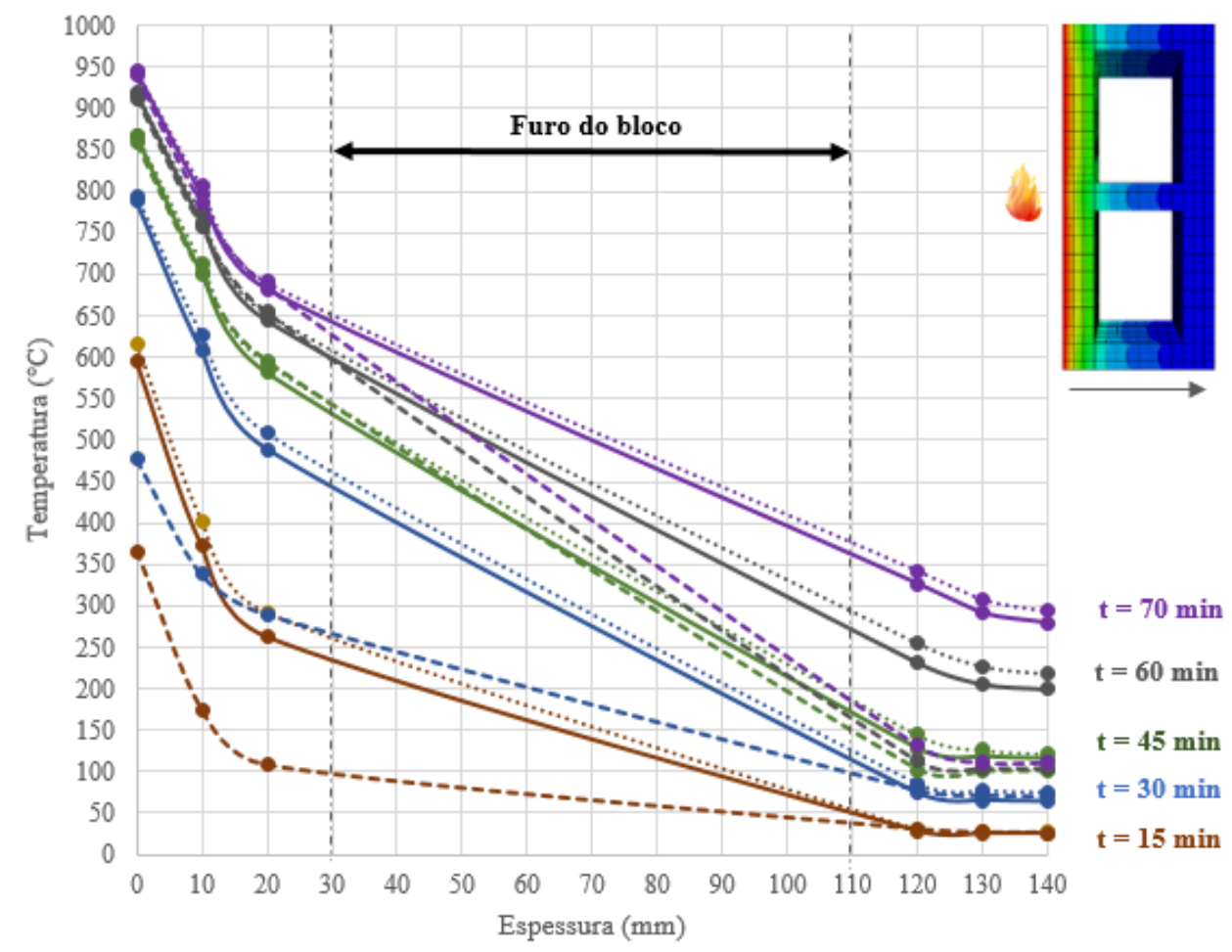

Figura 16 - Evolução da temperatura $\left({ }^{\circ} \mathrm{C}\right)$ ao longo do tempo $(\mathrm{min})$ utilizando o Eurocode 2 e a calibração do modelo para as propriedades térmicas

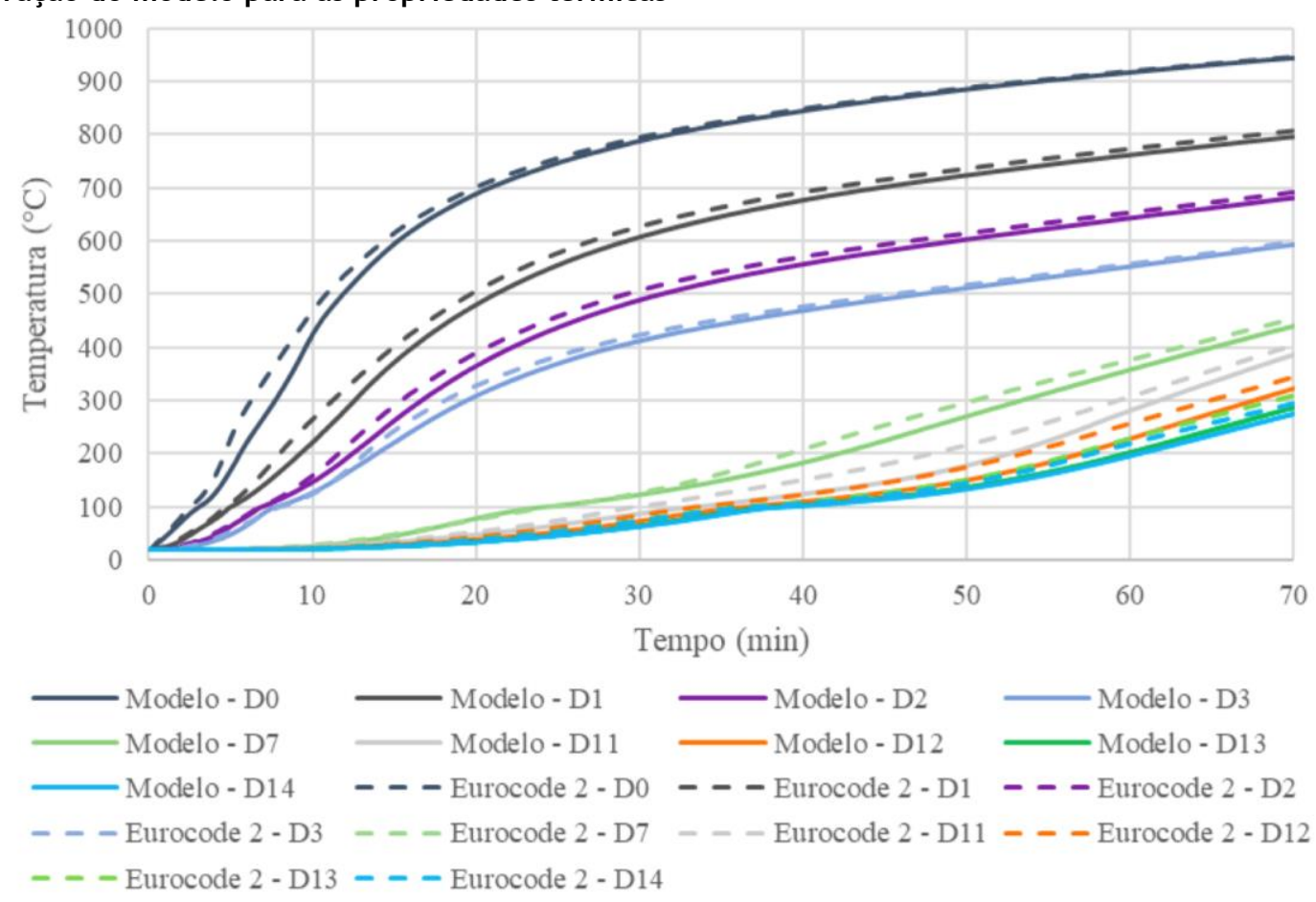


Figura 17 - Evolução da temperatura $\left({ }^{\circ} \mathrm{C}\right)$ ao longo do tempo $(\mathrm{min})$ utilizando o Eurocode 6 e a calibração do modelo para as propriedades térmicas

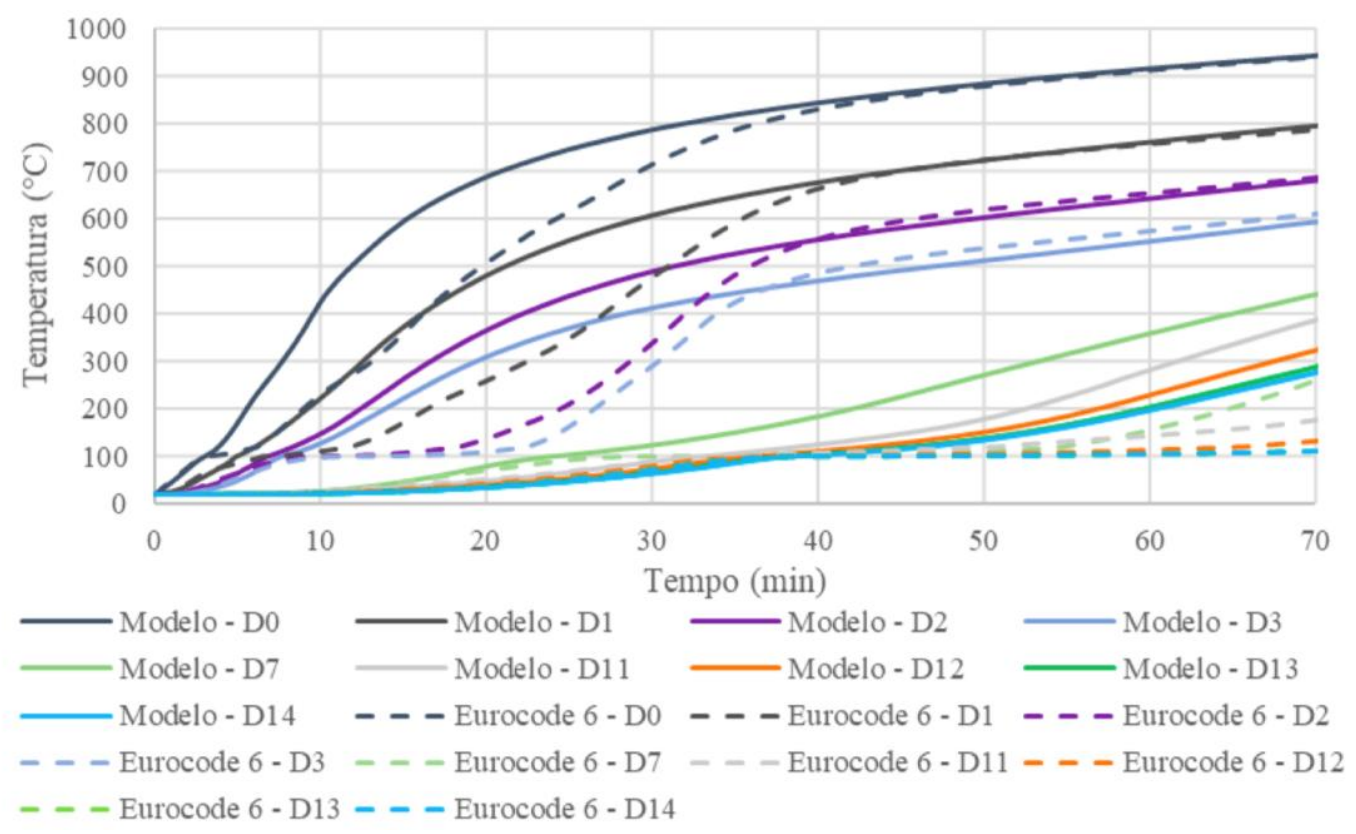

Em relação à resistência ao fogo da alvenaria segundo o critério de isolamento térmico, a Tabela 8 indica os valores obtidos nas três análises numéricas.

Verifica-se mais uma vez que os valores médios são os limitantes para as variações realizadas nesse tópico. Conforme esperado, de acordo com os resultados anteriormente analisados, o modelo calibrado apresenta resultados próximos aos do Eurocode 2 (EUROPEAN..., 2004a, 2004b); por outro lado, ocorre grande divergência em relação aos resultados do Eurocode 6 (EUROPEAN..., 2005a, 2005b), em decorrência do pico elevado de calor específico nas curvas desta norma, que tende a retardar a transferência de calor ao longo da seção transversal da parede. Ressalta-se que as propriedades térmicas fornecidas pelo Eurocode 6 se referem a materiais diferentes dos blocos de concreto brasileiros, tendo sido tomadas apenas como referência para a calibração dos parâmetros utilizados nas análises numéricas aqui apresentadas.

\section{Análise complementar 4: variação quanto ao refinamento da malha}

A presente análise avaliou a variação do refinamento da malha a partir do modelo validado anteriormente. Nesta análise foram utilizadas malhas com elementos finitos de dimensões iguais a $0,5 \mathrm{~cm}, 1,0 \mathrm{~cm} \mathrm{e} 1,5 \mathrm{~cm}$, para fins de discretização do modelo. A Tabela 9 indica as temperaturas obtidas para os mesmos pontos utilizando os três refinamentos propostos.

Ao analisar os resultados apresentados, é possível verificar pouca variação entre as malhas adotadas, na ordem de $15^{\circ} \mathrm{C}$ para uma distância de $7 \mathrm{~cm}$ da face exposta, e inferior a $3{ }^{\circ} \mathrm{C}$ nas demais medições, podendo ser consideradas desprezíveis em relação à ordem de grandeza das temperaturas máximas identificadas. As Figuras 18(a), 18(b), 18(c) e 18(d) ilustram o gradiente de temperaturas para os modelos com 15 min, 30 min, 45 min e 60 min de tempos de incêndio respectivamente. 
Tabela 8 - Critério de isolamento térmico $(\mathrm{min})$ obtido numericamente para comparação quanto às propriedades térmicas

\begin{tabular}{c|c|c}
\hline Referência & Valor médio & Valor máximo \\
\hline Eurocode 2 & 50 & 58 \\
Eurocode 6 & 84 & 89 \\
Modelo calibrado & 52 & 60 \\
\hline
\end{tabular}

Tabela 9 - Temperaturas $\left({ }^{\circ} \mathrm{C}\right)$ obtidas ao longo da espessura da parede para diferentes refinamentos de malha de acordo com o tempo ( $\mathrm{min})$ de incêndio

\begin{tabular}{c|c|c|c|c|c|c}
\hline \multirow{2}{*}{$\begin{array}{c}\text { Tempo de } \\
\text { incêndio } \\
(\mathbf{m i n})\end{array}$} & \multirow{2}{*}{$\begin{array}{c}\text { Malha } \\
(\mathbf{c m})\end{array}$} & $\begin{array}{c}\text { Face } \\
\text { exposta }\end{array}$ & $\begin{array}{c}\text { Septo interno } \\
\text { exposto }\end{array}$ & Meio & $\begin{array}{c}\text { Septo interno } \\
\text { oposto }\end{array}$ & $\begin{array}{c}\text { Face } \\
\text { oposta }\end{array}$ \\
\cline { 3 - 7 } $\mathbf{3}$ & 0,5 & 594,5 & 218,8 & 45,0 & 34,8 & 26,0 \\
& 1,0 & 594,6 & 221,9 & 46,3 & 34,5 & 26,0 \\
& 1,5 & 597,5 & 228,7 & 42,5 & 34,5 & 26,1 \\
\hline \multirow{3}{*}{$\mathbf{3 0}$} & 0,5 & 787,4 & 411,4 & 122,5 & 88,5 & 64,2 \\
& 1,0 & 787,4 & 412,5 & 123,6 & 87,8 & 63,6 \\
& 1,5 & 788,0 & 414,5 & 116,3 & 87,4 & 68,7 \\
\hline \multirow{3}{*}{$\mathbf{4 5}$} & 0,5 & 865,3 & 490,8 & 223,0 & 147,7 & 115,6 \\
& 1,0 & 865,9 & 491,8 & 226,6 & 147,8 & 115,7 \\
& 1,5 & 866,1 & 492,6 & 211,6 & 147,4 & 115,7 \\
\hline \multirow{2}{*}{$\mathbf{6 0}$} & 0,5 & 917,0 & 553,4 & 358,8 & 287,2 & 200,2 \\
& 1,0 & 917,0 & 553,7 & 361,5 & 285,7 & 199,7 \\
& 1,5 & 916,6 & 552,8 & 344,8 & 281,6 & 198,4 \\
\hline
\end{tabular}

Figura 18 - Esquematização do gradiente de temperaturas para as diferentes discretizações para 15 (a), 30 (b), 45 (c) e 60 (d) min de incêndio
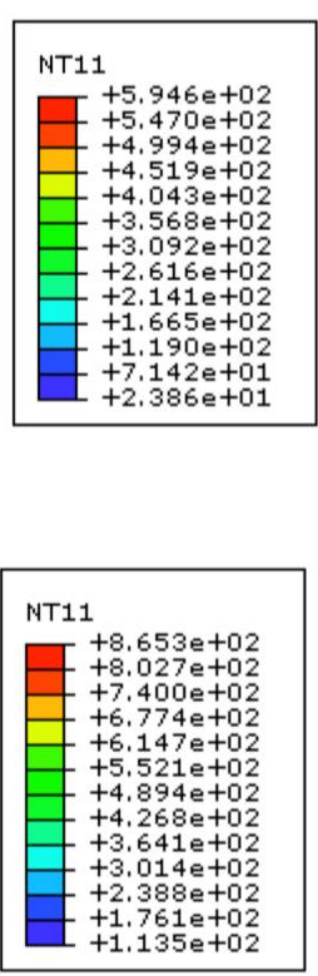
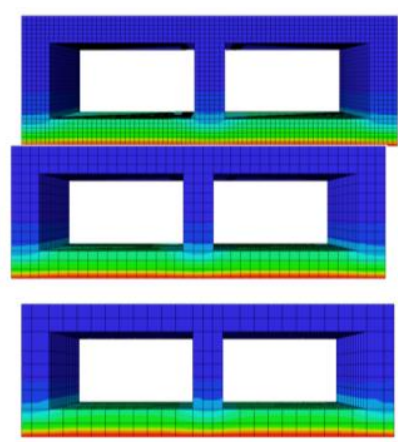

(a)
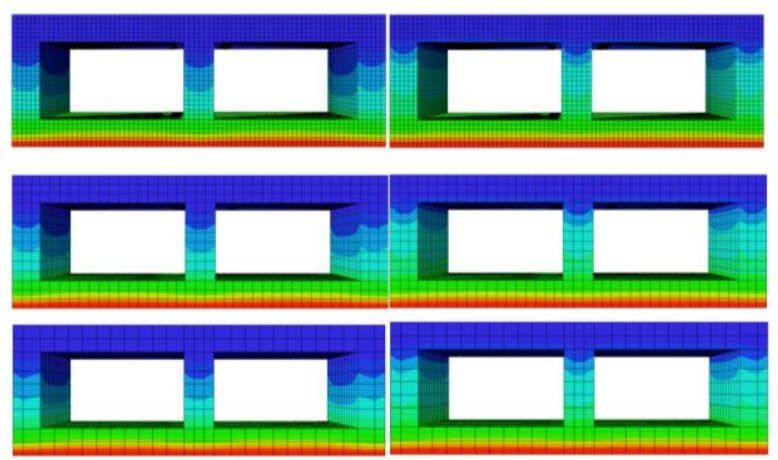

(c)

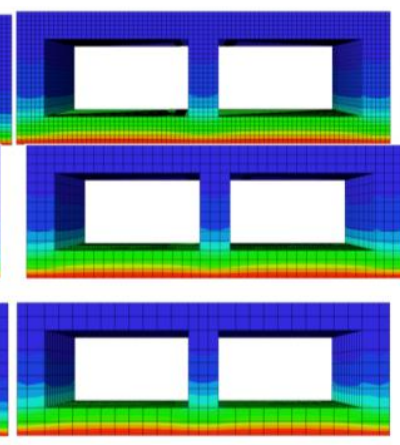

(b)

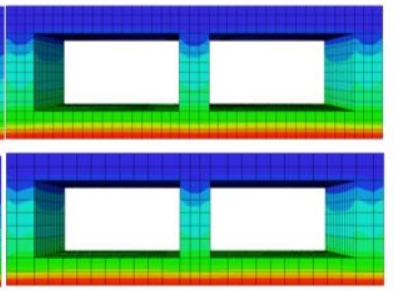

(d)
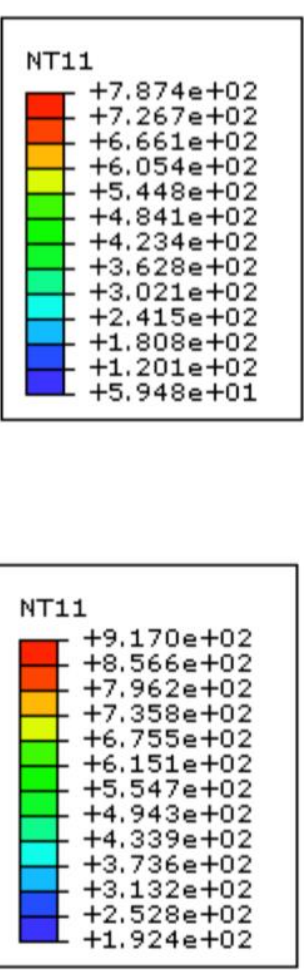

84 Carvalho, P. R. de O.; Leal, D. F.; Munair Neto, J. 


\section{Conclusão/considerações finais}

Entre os pontos de análise deste artigo destacam-se:

(a) fez-se necessária a calibração dos parâmetros de calor específico e condutividade térmica para os blocos estudados, em virtude da inexistência de curvas e equações para os materiais brasileiros (essa calibração foi baseada nos resultados experimentais de Dupim (2019) e nas prescrições do Eurocode 2 e do Eurocode 6);

(b) ao longo da seção transversal, verificou-se boa concordância dos resultados numéricos em relação aos experimentais para os tempos de incêndio estudados, principalmente no septo longitudinal dos blocos expostos ao fogo, onde foram obtidos desvios inferiores a $20^{\circ} \mathrm{C}$, equivalente a $3,1 \%$, e nos septos longitudinais da face não exposta ao fogo os desvios foram inferiores a $30{ }^{\circ} \mathrm{C}$, o que equivale a uma diferença de 9,9\%;

(c) para a análise da elevação de temperatura ao longo do tempo, as mesmas situações foram verificadas, resultando em curvas com boa concordância na face exposta em relação às curvas experimentais, com queda da precisão para a face não exposta ao fogo, enquanto em relação ao patamar aos $100{ }^{\circ} \mathrm{C}$ o modelo não conseguiu obter o mesmo padrão verificado experimentalmente;

(d) a ocorrência dos desvios citados anteriormente pode estar relacionada ao processo de fissuração ocorrido nas paredes ao longo do ensaio, situação não abordada na modelagem numérica, bem como às incertezas do próprio ensaio em virtude de desprendimentos dos mecanismos de colagem dos termopares, por exemplo;

(e) em relação à resistência ao fogo da alvenaria segundo o critério de isolamento térmico, o modelo atingiu o limite de elevação média da temperatura igual a $140^{\circ} \mathrm{C}$ aos $52 \mathrm{~min}$, enquanto o limite de elevação máxima de $180^{\circ} \mathrm{C}$ em qualquer ponto da face não exposta foi atingido aos $62 \mathrm{~min}$ na análise numérica, o que corresponde a uma diferença de 2 min em relação ao resultado experimental;

(f) as curvas de evolução de temperatura ao longo do tempo para a situação com fogo em ambas as faces mostram tendências semelhantes entre os resultados numéricos e experimentais, apresentando diferenças inferiores a $50{ }^{\circ} \mathrm{C}$ em relação aos limites experimentais, as quais resultam inferiores a $6 \%$;

(g) o modelo numérico aqui apresentado se mostra bastante consistente quando comparado a resultados experimentais presentes na literatura, o que pode ser bastante útil na avaliação da resistência ao fogo de edifícios de alvenaria estrutural construídos com blocos vazados de concreto; e

(h) além das análises quanto ao critério de isolamento térmico, há grande carência de pesquisas para a avaliação da alvenaria estrutural quanto aos demais critérios de resistência ao fogo constantes nas normas (resistência mecânica e integridade), tanto em contexto experimental quanto numérico.

Considerando o fato de não haver procedimentos normalizados para a avaliação da alvenaria estrutural em situação de incêndio no Brasil, torna-se de grande importância a realização de mais ensaios experimentais e o desenvolvimento de modelos numéricos termoestruturais confiáveis para a avaliação da alvenaria mediante a atuação conjunta de ações térmicas e mecânicas.

\section{Referências}

AL NAHHAS, F. et al. Resistance to fire of walls constituted by hollow blocks: experiments and thermal modeling. Applied Thermal Engineering, v. 27, n. 1, p. 258-267, 2007.

AL-HADHRAMI, L. M.; AHMAD, A. Assessment of thermal performance of different types of masonry bricks used in Saudi Arabia. Applied Thermal Engineering, v. 29, p. 1123- 1130, 2009.

ANDREINI, M. et al. Mechanical behavior of masonry materials at high temperatures. Fire and Materials, v. 39, n. 1, p. 41-57, 2014.

ASSOCIAÇÃO BRASILEIRA DE NORMAS TÉCNICAS. NBR 15200: projeto de estruturas de concreto em situação de incêndio. Rio de Janeiro, 2012.

ASSOCIAÇÃO BRASILEIRA DE NORMAS TÉCNICAS. NBR 14432: exigências de resistência ao fogo de elementos construtivos de edificações: procedimento. Rio de Janeiro, 2001.

ASSOCIAÇÃO BRASILEIRA DE NORMAS TÉCNICAS. NBR 15575-4: edificações habitacionais: desempenho: parte 4: requisitos para os sistemas de vedações verticais internas e externas - SVVIE. Rio de Janeiro, 2013. 
BONITESE, K. V. Segurança contra incêndio em edifício habitacional de baixo custo estruturado em aço. Belo Horizonte, 2007. 253 f. Dissertação (Mestrado em Engenharia Civil) - Universidade Federal de Minas Gerais, Belo Horizonte, 2007.

CARVALHO, P. R. O. Análise numérica de pequenas paredes de alvenaria estrutural de blocos de concreto em situação de incêndio: ênfase no comportamento térmico e termoestrutural. São Carlos, 2019. 313 f. Dissertação (Mestrado em Engenharia Civil) - Escola de Engenharia de São Carlos, Universidade de São Paulo, São Carlos, 2019.

CENTRE OF FIRE STATISTICS. World fire statistics. Report n. 21. International Association of Fire and Rescue Services, 2016.

CHICHIERCHIO, L. C. Conforto ambiental: desempenho térmico e acústico e proteção contra o fogo. In: ASSOCIAÇÃO BRASILEIRA DA CONSTRUÇÃO INDUSTRIALIZADA. Manual técnico de alvenaria. São Paulo: ABCI, 1990.

CORPO DE BOMBEIROS DO ESTADO DE SÃO PAULO. IT 08/2011: resistência ao fogo dos elementos de construção. São Paulo, 2011. Instrução técnica Nº 08.

DUPIM, R. H. Resistência residual de compressão de blocos, prismas e pequenas paredes de alvenaria estrutural de blocos de concreto submetidos à situação de incêndio. São Carlos, 2019. Dissertação (Mestrado em Engenharia Civil) - Escola de Engenharia de São Carlos, Universidade de São Paulo, São Carlos, 2019

EUROPEAN COMMITTEE FOR STANDARDIZATION. Eurocode 2: design of concrete structures: part 1.1: general rules and rules for buildings. Bruxelas, 2004a.

EUROPEAN COMMITTEE FOR STANDARDIZATION. Eurocode 2: design of concrete structures: part 1.2: general rules: structural fire design. Bruxelas, 2004b.

EUROPEAN COMMITTEE FOR STANDARDIZATION. Eurocode 6: design of masonry structures: part 1.1: general rules for reinforced and unreinforced masonry structures. Bruxelas, 2005a.

EUROPEAN COMMITTEE FOR STANDARDIZATION. Eurocode 6: design of masonry structures: part 1.2: general rules: structural fire design. Bruxelas, 2005b.

INTERNATIONAL ORGANIZATION FOR STANDARDIZATION. ISO 834: fire resistance tests: elements of building construction: part 1: general requirements. Gèneve, 1999.

LOPES, R. F. R. et al. Análise experimental de uma parede de alvenaria estrutural de blocos de concreto de três células em situação de incêndio. Concreto e Construções, v. 90, p. 86-94, abr./jun. 2018.

NADJAI, A. et al. Compartment masonry walls in fire situations. Fire Technology, v. 42, p. 211-231, 2006.

OLIVEIRA, L. A. P. de. Estimativa da resistência ao fogo de paredes de alvenaria pelo critério de isolamento térmico. Boletim Técnico da Faculdade de Tecnologia de São Paulo, n. 5, dez. 1998. Disponível em: http://bt.fatecsp.br/system/articles/26/original02luizantonio.pdf. Acesso em: 15 set. 2018.

OLIVEIRA, L. M. F. Estudo teórico e experimental do comportamento das interfaces verticais de paredes interconectadas de alvenaria estrutural. São Carlos, 2014. Tese (Doutorado em Engenharia Civil) - Escola de Engenharia de São Carlos, Universidade de São Paulo, São Carlos, 2014.

RIGÃO, A. O. Comportamento de pequenas paredes de alvenaria estrutural frente a altas temperaturas. Santa Maria, 2012. 142 f. Dissertação (Mestrado em Engenharia Civil) - Escola de Engenharia, Universidade Federal de Santa Maria, Santa Maria, 2012.

RODOVALHO, F. S. Simulação numérica de blocos e prismas de alvenaria em situação de incêndio. São Carlos, 2018. 158 f. Dissertação (Mestrado em Engenharia Civil) - Escola de Engenharia de São Carlos, Universidade de São Paulo, São Carlos, 2018.

ROSEMANN, F. Resistência ao fogo de paredes de alvenaria estrutural de blocos cerâmicos pelo critério de isolamento térmico. Florianópolis, 2011. 160 f. Dissertação (Mestrado em Engenharia Civil) Universidade Federal de Santa Catarina, Florianópolis, 2011.

SANTOS, C. F. R. et al. Thermo-structural modeling of clay units masonry walls under fire conditions. Florianópolis: Cilamce, 2017.

SOARES, S. M. B. Alvenaria estrutural. Porto Alegre: Pontifícia Universidade Católica do Rio Grande do Sul, 2010. 


\section{Paulo Roberto de Oliveira Carvalho}

Escola de Engenharia de São Carlos, Departamento de Engenharia de Estruturas | Universidade de São Paulo | Av. Trabalhador São-

Carlense, 400, Parque Arnold Schimidt | São Carlos - SP - Brasil | CEP 13566-300 | Tel.: (16) 3373-9455 | E-mail: proc00012@gmail.com

Davi Fagundes Leal

Instituto Federal de Educação, Ciência e Tecnologia Fluminense | Rua Dr. Siqueira, 273, Parque Dom Bosco, Campus Campos-Centro | Campos dos Goytacazes - RJ - Brasil | CEP 28030-130 | Tel.: (22) 2726-2800 | E-mail: daviusp@sc.usp.br

\section{Jorge Munaiar Neto}

Escola de Engenharia de São Carlos, | Departamento de Engenharia de Estruturas | Universidade de São Paulo | E-mail: jmunaiar@sc.usp.br

\section{Ambiente Construído}

Revista da Associação Nacional de Tecnologia do Ambiente Construído

Av. Osvaldo Aranha, $99-3^{\circ}$ andar, Centro

Porto Alegre - RS - Brasil

CEP 90035-190

Telefone: +55 (51) 3308-4084

www.seer.ufrgs.br/ambienteconstruido www.scielo.br/ac

E-mail: ambienteconstruido@ufrgs.br

(c) (1) This is an open-access article distributed under the terms of the Creative Commons Attribution License. 